\title{
ARQUEOLOGÍA Y ARQUITECTURA DE SAN MARTIÑO DE MONDOÑEDO (FOZ, LUGO). REVISIÓN CRÍTICA Y NUEVAS APORTACIONES
}

\author{
José Carlos Sánchez-Pardo \\ Javier Castiñeiras López \\ Universidade de Santiago de Compostela \\ Jorge Sanjurjo-Sánchez \\ Universidade da Coruña
}

Data recepción: 2017/04/15

Data aceptación: 2018/06/07

Contacto autores: josecarlos.sanchez@usc.es; javier.castineiras84@gmail.com; jorge.sanjurjo.sanchez@udc.es

ORCID: https://orcid.org/0000-0003-2899-4951

ORCID: https://orcid.org/0000-0002-1155-4987

ORCID: https://orcid.org/0000-0002-7559-8647

\section{RESUMEN}

En este trabajo se pretende, en primer lugar, revisar y analizar de forma crítica y comparada toda la información histórico-artística y arqueológica existente sobre San Martiño de Mondoñedo, para posteriormente ofrecer algunos nuevos datos sobre los orígenes y evolución de este emblemático edificio entre la Alta y Plena Edad Media. Para ello nos basaremos en una aproximación arqueológica a los paramentos del edificio así como en la datación mediante Luminiscencia y Radiocarbono de diversos elementos de la cúpula de este edificio. Frente a las ideas tradicionalmente sostenidas, los resultados preliminares, a falta de nuevos y necesarios estudios, sugieren que no hay indicios para hablar de una ocupación del siglo VI en el lugar, y que el edificio románico actual, pese a emplear piezas reutilizadas, no parece presentar restos de muros prerrománicos en pie. Por su parte, la datación de morteros de la cúpula confirma su construcción en el siglo XII.

Palabras clave: San Martiño de Mondoñedo, análisis arqueológico, arquitectura prerrománica, necrópolis altomedievales, datación por luminiscencia

\section{ABSTRACT}

This paper aims to offer a critical and comparative review and analysis of the historical-artistic and archaeological information pertaining to San Martiño de Mondoñedo and to then provide some new information on the origins and evolution of this iconic building, which dates to the period between the early and central Middle Ages. In doing so, we have adopted an archaeological approach to the walls of the building and conducted luminescence and radiocarbon dating of samples from the dome. Contradicting traditionally held ideas, the preliminary results (which require confirmation in future studies), suggest that there is no evidence of the site having been settled in the 6th century and that the existing Romanesque building does not comprise standing sections of pre-Romanesque walls, though it does contain some reused pieces. Mortar from the dome has been dated, providing confirmation that it was built in the 12th century.

Keywords: San Martiño de Mondoñedo, archaeology of architecture, pre-Romanesque architecture, early medieval burials, luminescence dating 


\section{Introducción'}

San Martiño de Mondoñedo (Foz, Lugo) es sin duda un lugar emblemático a nivel artístico, arqueológico e histórico. Este enclave está íntimamente relacionado con los orígenes de la diócesis de Mondoñedo, ya que en él diversos autores han situado el enigmático "monasterio Maximi" o bien la famosa y discutida sede de Britonia, que aparecen mencionados en el documento conocido como "Parroquial Suevo" hacia finales del siglo $\mathrm{Vl}^{2}$. Al margen de estas hipótesis, lo que parece aceptado es que desde finales del siglo IX, con el apoyo de la monarquía asturiana, San Martiño fue el asiento de la nueva sede episcopal mindoniense, hasta que se traslada al actual Mondoñedo en el s. XII3.

Esta realidad histórica se ha plasmado en un importante conjunto artístico y arqueológico compuesto por una singular basílica que constituye una de las más tempranas y destacadas expresiones del románico en el Noroeste peninsular (fig. 1), y que conserva distintos elementos prerrománicos en su fábrica, así como por un yacimiento arqueológico bajo y entorno a la misma formado por una necrópolis y diversas estructuras asociadas a los edificios religiosos que ocuparon este lugar 4 .

Sin embargo, los estudios de carácter histórico-artístico y aquellos realizados desde una perspectiva arqueológica sobre San Martiño se han efectuado generalmente de forma separada, de modo que los historiadores del arte se han centrado únicamente en el edificio, mientras que los arqueólogos se han dedicado a analizar los restos conservados bajo tierra. Este hecho ha impedido aprovechar adecuadamente la complementariedad de la información generada por ambos tipos de aproximaciones, si bien cada vez es más evidente que el análisis arqueológico, no sólo del subsuelo, sino también de los paramentos a través del método estratigráfico, puede ofrecer importante información de interés para la Historia del Arte, al igual que, viceversa, es imprescindible la información histórico-artística para contextualizar las evidencias arqueológicas.

En este trabajo pretendemos, en primer lugar, revisar y analizar de forma crítica y comparada toda la información histórico-artística y arqueológica existente sobre San Martiño, para poste-

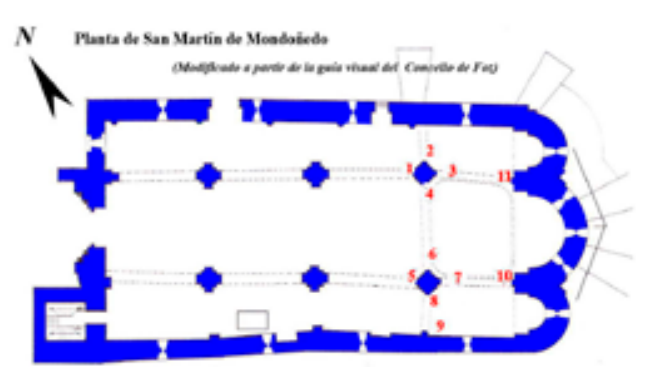

Fig. 1. Planta de San Martiño de Mondoñedo, modificada a partir de la guía visual del Concello de Foz.

riormente ofrecer algunos nuevos datos sobre los orígenes y evolución de este emblemático edificio entre la Alta y Plena Edad Media. Para ello nos basaremos en una aproximación arqueológica a los paramentos del edificio así como en la datación mediante Luminiscencia y Radiocarbono de diversos elementos de la cúpula de este edificio realizada en 2007 y que permanecía inédita (fig. 1).

\section{San Martiño de Mondoñedo. Un estado de la cuestión}

\subsection{Los estudios sobre San Martiño}

"La Iglesia es la mejor fábrica de las antiguas de la Diocesi, conservando aun en lo material la prerogativa de haber sido cathedral. Es de tres naves, toda de piedra de Sillería"5. Con estas palabras del tomo XVIII de la España Sagrada, el padre Flórez nos proporciona la que podríamos considerar primera exégesis del edificio románico de San Martiño de Mondoñedo. A pesar de lo parco de la información de tipo histórico-artístico, el historiador de la iglesia inaugura una larga tradición historiográfica que posicionará a la antigua sede catedralicia entre los ejemplos pioneros del románico en tierras del noroeste hispano.

Con la publicación de "San Martín de Mondoñedo (Antigua catedral)" en el número de la revista Galicia Diplomática del 11 de marzo de 1888, José Villaamil y Castro realiza el primer estudio de la fábrica con criterios que podríamos considerar histórico-artísticos. El estudio fue reeditado en Iglesias Gallegas de la Edad Media en 1904, convirtiéndose en la piedra fundacional de todos los trabajos posteriores y sentando las bases de la valoración del edificio como monu- 
mento. El análisis está estructurado en tres partes diferenciadas: un estudio histórico de la sede, una descripción de la arquitectura y un análisis de la escultura de la fábrica románica. En este último campo, Villaamil se muestra especialmente interesado y considera que "La verdadera importancia arqueológica de esta iglesia está en su riqueza iconográfica" ${ }^{\prime \prime}$. La descripción de las escenas es minuciosa, con algunos errores de identificación, y va acompañada de unos excelentes dibujos de los principales capiteles historiados y del antipendio o frontal de altar. El trabajo de Villaamil inaugura y "redescubre" San Martiño de Mondoñedo pero prescinde de cualquier valoración de tipo comparativo y no establece ningún tipo de paralelo con otros talleres del románico europeo o peninsular.

En la progresiva revalorización de la antigua sede catedralicia de Mondoñedo, jugó un papel fundamental la intervención arqueológica llevada a cabo por Manuel Chamoso Lamas en 1967, de la que hablaremos de manera detallada posteriormente. Aunque la información que este autor nos dejó sobre su intervención no es demasiado prolija, sí realizó un amplio corpus fotográfico sobre el edificio que hoy se custodia digitalizado en la Real Academia Gallega de Bellas Artes.

En 1972 Ángel del Castillo en su Inventario de la riqueza monumental y artística de Galicia propone también una descripción detallada de su arquitectura. Es destacable como el autor ya utiliza el término "lombardo" para referirse a las pequeñas arcuaciones que recorren las cornisas de los ábsides, para después utilizar el adjetivo "catalana" para su arquitectura. Al margen de la problemática terminológica, se pone de manifiesto el origen de estas formas arquitectónicas entre Cataluña y el norte de Italia. Además de exponer su lectura de la arquitectura, el historiador coruñés destaca los trabajos en escultura, "interesantísima en técnica y asuntos", incluyendo al célebre antipendio. Termina la entrada del inventario enumerando piezas del ajuar litúrgico, entre las que se encuentra el báculo románico, y las pinturas parietales que califica genéricamente de "medievales". Al margen del valor descriptivo del inventariado, Ángel del Castillo apunta hacia un análisis de filiación importante al definir la fábrica como "románico primitivo de Galicia, ajeno desde luego a lo compostelano"7. Esta afirmación resulta fundamental ya que el autor identifica una segunda vía en el proceso de creación románico en la Galicia de los años finales del siglo XI.

Un año más tarde sale a la luz Galice Romane de M. Chamoso, V. González y B. Regali. Uno de los principales aciertos de este estudio es la inclusión de la construcción en un estudio general sobre el románico gallego, ofreciendo así un análisis diacrónico que permitió situar a la obra en su contexto histórico y monumental. El texto de Regal es el más completo de su tiempo y establece las bases para todos los trabajos que a partir de la década de los noventa y hasta nuestros días, se han ocupado del edificio. La inclusión de San Martiño de Mondoñedo en la Galice Romane supuso además, un "lanzamiento" del templo gallego hacia la comunidad científica internacional, al ser esta una obra editada en Francia y publicada en francés.

En 1978 Manuel Núñez, en el marco de su tesis doctoral sobre la arquitectura prerrománica en Galicia', aborda por primera vez de forma específica el análisis de los restos prerrománicos conservados en San Martiño y la posible configuración de la primitiva y desparecida iglesia altomedieval. En el año 1980 S. San Cristobal publica un trabajo titulado La antigua catedral de San Martín de Mondoñedo ${ }^{10}$. En este estudio monográfico en XI capítulos, el historiador y canónigo sigue el testigo de sus predecesores y a partir de ello nos ofrece un acercamiento a la historia de la sede, una descripción formal del edificio y un recorrido por algunos de los principales hitos acaecidos en su azarosa historia. Resulta de un especial interés la exposición de las reformas y añadidos, retomando la senda marcada por el trabajo de Villaamil.

Este breve repaso por los trabajos fundamentales que han posicionado a San Martiño de Mondoñedo en un lugar de relevancia dentro de la geografía artística del románico hispano, no estaría completo sin las aportaciones de Ramón Yzquierdo y Manuel A. Castiñeiras. Los trabajos de ambos autores son hasta la fecha, los estudios más completos sobre la iglesia románica y los que se han acercado a su fábrica desde una óptica y una metodología más rigurosas. El trabajo de Ramón Yzquierdo es la monografía de referencia 
para el estudio de la construcción románica"1. En ella se recogen todas las afirmaciones de los autores precedentes y se ofrece una completa panorámica del devenir histórico del edificio. Pero sin duda, la gran aportación del historiador del arte es el análisis pormenorizado y concienzudo de la arquitectura del edificio. A través de este análisis metódico el autor concluye, de modo muy resumido, que a la fase prerrománica de la fábrica se le superponen tres campañas ya románicas entre los años finales del siglo XI e inicios del siglo XII. EI testigo de este estudio fue tomado por Manuel A. Castiñeiras, cuyos análisis se exponen en diversas publicaciones $^{12}$.

En apartados siguientes trataremos de exponer la lectura del edificio que proponen ambos autores, pero de modo general podemos adelantar que para Ramón Yzquierdo en la fábrica románica se diferencian tres fases constructivas Ilevadas a cabo a caballo entre los siglos XI y XII, mientras que para Castiñeiras la gran unidad del proyecto lleva a minimizar el impacto del último de estos talleres. Ambos autores destacan, como ya había hecho Villaamil, la excepcionalidad y riqueza del conjunto escultórico. Castiñeiras se detiene más en este respecto y propone una lectura completa del programa y establece una serie de filiaciones estilísticas. Finalmente, este mismo autor, se ha ocupado del estudio de las pinturas murales románicas redescubiertas tras las intervenciones de restauración y limpieza de los años 2007 y 2008 llevadas a cabo por la restauradora Blanca Besteiro. Fruto de estos trabajos son diversas publicaciones recientes ${ }^{13}$.

Aprovechando estas mismas labores de restauración, se realizaron distintos sondeos arqueológicos tanto en la huerta de la casa rectoral como en la sacristía, que fueron dirigidos por Celso Rodríguez Cao y Luis Cordeiro Maañón. Esta intervención ha supuesto una importante renovación de la información existente sobre la arqueología de este lugar, como veremos más adelante.

Los trabajos enumerados, junto a los de $\mathrm{A}$. López Valcarcel14, N. Peinado Gómez ${ }^{15}$, N. Rielo Carballo ${ }^{16}$, J. Yarza Luaces ${ }^{17}$, o I. Bango Torviso entre otros ${ }^{18}$, dibujan una construcción pionera en el ámbito geográfico peninsular cuya realidad figurativa y arquitectónica pasamos a esbozar.

\subsection{La primitiva iglesia prerrománica}

Todos los autores admiten que existió, por lo menos, una iglesia prerrománica anterior al edificio románico, datable entre los siglos IX y X. Para Núñez esta etapa prerrománica se dataría entre los años 927 y 940, a partir de una construcción anterior que hundiría sus raíces en época visigoda. Podría haber sido un edificio de nave única, con accesos en los muros norte y sur. En ese sentido el propio edificio románico actual todavía mostraría mucha herencia astur: estrechez de las naves, iluminación directa a través de ventanas abiertas en la misma nave mayor, sillares pequeños, muros organizados con fuertes pilares, etc ${ }^{19}$. Para este autor la fábrica supuestamente conservada de esta iglesia prerrománica, en los niveles inferiores de los muros norte y sur así como en parte de la fachada oeste, correspondería a un aparejo a soga y tizón muy irregular, realizado con sillares pequeños, como en San Martiño de Pazó, Santa Eufemia de Ambía o Vilanova dos Infantes, todas ellas en la provincia Ourense. Para ello se habrían seleccionado sillares con cierto efecto de almohadillado, algo que se ve favorecido por el corte de las rocas de esta zona (principalmente granito y metasedimentos) ${ }^{20}$.

Para Yzquierdo se trataba probablemente de una iglesia de tres naves, muy ancha pero más corta que la actual, con ventanas de arco de herradura descentrada. La disparidad de restos y lo fragmentario de su estado harían difícil precisar su cronología, que "más por intuición y lógica que por objetividad, suele situarse en el episcopado de San Rosendo"21. Esta iglesia aun se encuadraría en la tradición asturiana pero presentando ya algunos primeros elementos de arte de repoblación. Por ello considera que se podría datar entre el 925 y quizá 944, cuando San Rosendo fue obispo mindoniense, concluyéndose en torno al 950, con el obispo Aylus. En todo caso, continúa este autor, seguiría siendo discutido si aquí radicó el monasterio Maximo ${ }^{22}$. En un trabajo posterior, en 2007, este autor distingue algunas piezas del siglo IX, datables por tanto en un primer edificio construido hacia el 870, tras la restauración de la sede episcopal por Alfonso III en este lugar, de otras del siglo $X$, ya de época rosendiana, lo cual nos llevaría a al menos dos fases prerrománicas, 
sin contar las piezas de una posible edificación del siglo VI-VII23.

Por su parte, Castiñeiras habla de una única fábrica prerrománica del siglo $X$, por iniciativa de San Rosendo y que podría haber sido construida en paralelo a la iglesia monástica de Celanova, entre 936 y 942. Como Núñez, este autor, también piensa que la primitiva iglesia debió condicionar en buena medida la disposición y distribución del templo románico. Seguramente se trataba de una basílica (en base a los restos perimetrales conservados), de tres naves, cuyo cuerpo principal coincidiría con las dimensiones actuales de las naves, siguiendo el modelo habitual en la arquitectura asturiana. Por otro lado, la puerta en la cara norte, que este autor considera que habría sido originalmente de arco de herradura, sería indicio de la existencia de un espacio reservado a la comunidad monástica, lo que llevaría a plantear una planta basilical de tres tramos, más un tramo de transepto (señalado por la puerta con alfiz) y una cabecera de tres ábsides rectos, como en las iglesias de O Cebreiro (Lugo) y Mixós (Ourense). Sería, pues, una iglesia más corta que la actual pero de igual anchura24.

\subsection{La fábrica románica. Un ambicioso pro-} yecto arquitectónico

La fábrica románica de San Martiño de Mondoñedo ocupa con todo merecimiento un lugar preponderante en la historiografía artística gallega y española. Si exceptuamos la incomparable empresa compostelana en tiempos de Diego Peláez, el templo mindoniense es la plasmación más madura y compleja de los escasos ejemplos que del primer románico han llegado a nuestros días en el territorio gallego. En las próximas líneas realizaremos un breve análisis del edificio románico en su vertiente arquitectónica y plástica, haciendo hincapié en sus posibles modelos y derivaciones.

En su visión actual, la planta y el alzado de San Martiño de Mondoñedo conservan grosso modo su aspecto románico. La planta presenta tres naves con una cabecera también tripartita con ábsides de perfil semicircular precedida de un espacio presbiteral de reducidas dimensiones. La tipología planimétrica empleada es muy poco común en la arquitectura gallega de los siglos altomedievales y el modelo basilical de tres naves es el más complejo de la arquitectura del primer románico en Galicia (insistimos en que debe exceptuarse la obra compostelana donde la complejidad espacial no tiene parangón). La disposición de tres naves con cabecera triple se encuentra también en la iglesia tudense de San Bartolomé de Rebordáns, si bien las diferencias con el edificio lucense son palpables: frente a los hemiciclos de San Martiño, los ábsides originarios de Rebordáns se remataban con testero recto y en los extremos del presbiterio se abrían dos pequeñas capillas, hoy desaparecidas, siguiendo modelos arquitectónicos que se remontan a los sacraria hispanos altomedievales. El resultado espacial es mucho menos integrador y uniforme que el de la iglesia catedralicia de Mondoñedo. La utilización del hemiciclo como forma de remate de los testeros se introduce paulatinamente en algunos de las fábricas del románico inicial gallego (San Xoán de Vilanova en Perbes o en las capillas de San Juan, San Pedro y el Salvador en la catedral compostelana) y convive en este periodo de finales del $\mathrm{XI}$, con tradiciones algo más retardatarias con remates de testero rectos (Rebordáns y Toques).

En alzado esta arquitectura viene definida principalmente por los siguientes elementos: arquillos ciegos dispuestos bajos los aleros de los ábsides, un uso de aparejo regular de reducidas dimensiones, la inclusión de un cimborrio sobre trompas y una articulación espacial novedosa. Estos elementos tienen su origen en la tradición constructiva del primer románico que en la Península Ibérica tuvo un enorme desarrollo y temprana aparición a inicios del siglo XI en el ámbito catalano-aragonés. Ha sido planteado que la entrada de estas corrientes en la Galicia de finales del XI debió producirse a través del territorio leonés, donde pueden encontrarse ejemplos constructivos de esta gramática edilicia, como Nuestra Señora de la Anunciada de Urueña o San Pelayo de Perazancas. La aparición de este léxico en el los reinos occidentales se ha puesto en relación con la llegada a la cátedra palentina de una serie de obispos, encabezados por Poncio de Tabérnoles en 1033, formados en el círculo cultural de la abadía de Ripoll del abad Oliba25.

Estas características formales son completamente novedosas en el territorio gallego pero como señala R. Yzquierdo estamos ante "un arte fuera de tiempo y de contexto" ${ }^{26}$. Aunque la afirmación resulta demasiado rotunda, no cabe duda 
que frente al caso catalán donde estas formas se ensayan a inicios de siglo, en Galicia su existencia no se puede constatar antes del último tercio del siglo XI. Junto a esta corriente o tendencia propia del primer románico, convive en San Martiño de Mondoñedo una segunda vía vinculada a las vías de peregrinación ${ }^{27}$. Canecillos en los aleros o el taquedado comúnmente conocido con el término de jaqués, son buena muestra de estos talleres conocedores del incipiente "arte de peregrinación".

\subsection{La plástica monumental. Un taller ajeno a Compostela}

Junto a una arquitectura novedosa, en San Martiño se encuentra uno de los ciclos plásticos más ricos y de cronología más temprana en el conjunto del arte románico de Galicia. El conjunto de capiteles esculpidos se concentra en el espacio del crucero: dos en las columnas entre la capilla mayor y las laterales, ocho en los soportes de los pilares compuestos que inician el primer tramo de las naves y uno en una columna adosada al muro norte. El taller que los confecciona no es especialmente hábil y la talla resulta demasiado plana. Los maestros que aquí trabajan se adecúan con cierta solvencia al soporte pero las calidades plásticas son bajas y poco o nada hay del imperante estilo hispano-languedociano, de gusto clásico, imperante en muchas obras coetáneas. Las figuras se conciben con unos grandes ojos y manos que complementan un rico lenguaje gestual que resulta muy convincente en términos narrativos a pesar de las carencias técnicas. El estilo parece mirar directamente a tradiciones previas más que al lenguaje de su tiempo y las similitudes en el modo de entender la composición de la imagen, recuerdan a la iluminación de códices en la Alta Edad Media hispana.

Algunos de los capiteles desarrollan decoración vegetal y geométrica pero en la mayoría de ellos los maestros se decantaron por imágenes narrativas. La variedad de temas es amplia y va desde representaciones de tipo animalístico a recreaciones de algunos pasajes de las Escrituras. La lectura de varios modelos iconográficos es clara y puede proponerse sin demasiados problemas una filiación, pero algunos ejemplos desarrollan tipos iconográficos cuya identificación genera importantes dudas. Los temas zoomórficos son abundantes, carecemos de espacio en este trabajo para exponer una lectura individualizada de cada uno de ellos pero sirva como ejemplo de su variedad, la presencia de grifos, équidos, aves, e incluso animales menos representados como la liebre. De entre las representaciones antropomorfas han llamado especialmente la atención de los investigadores los dos capiteles con cenáculos: el festín de Herodes y la degollación del Bautista, y la parábola del pobre Lázaro y el rico Epulón. La composición de los dos es similar: en la cara principal del capitel se dispone la escena central y se completa el relato en las caras menores. Es quizá en estos dos ejemplos donde el maestro explote con mayor éxito la cesta del capitel como soporte narrativo y a pesar de las limitaciones formales ya expuestas, consigue trenzar una narración en varios pasajes articulada en gran medida por la gestualidad y disposición de la figura en el espacio.

Señalaban ya los trabajos de Á. del Castillo que el taller que trabaja en los capiteles del crucero de San Martiño de Mondoñedo representaba un hacer escultórico ajeno a lo compostelano28. Entendemos que esta afirmación es válida pero algunos de los temas que se pueden observar en Mondoñedo también se encuentran en la catedral compostelana, como el célebre capitel con la mujer amamantando o siendo mordida por sapos que se encuentra en ambos edificios (también en San Bartolomé de Rebordáns).

Obra del mismo taller es el conocido Antipendio que hoy se expone en la capilla mayor. Estilísticamente no cabe duda de que son las mismas manos las que están trabajando en él, y las figuras se emparentan con aquellas de los capiteles. Su identificación genera grandes controversias. Existe un cierto quorum al aceptar la temática de tipo apocalíptico pero resulta muy complicado aventurar una identificación concreta. El tipo de temática así como el estilo de la composición han llevado a pensar en un Beato como modelo para el taller29. Sea como fuere, estamos ante una cuestión abierta ${ }^{30}$.

El taller de Mondoñedo encarna un punto intermedio, de frontera conceptual, en la que coexisten elementos formales y temáticos de herencia altomedieval, con otros de una madurez ya románica como la forma de adecuarse y comprender el capitel como sostén de la imagen. 


\subsection{Fases y cronología de la fábrica románica}

De modo general se fecha el inicio de la fábrica románica de San Martiño en una cronología en torno a las décadas finales del siglo XI. Para R. Yzquierdo la construcción de la iglesia fue larga y compleja. El inicio de las obras se produjo en los años iniciales del obispado de Gonzalo de Mondoñedo (1077-1108), empezando por la cabecera y continuando por los muros perimetrales. En la fase inicial se completaron las capillas norte y sur y se comenzó la elevación de la mayor hasta el nivel de las ventanas. En una segunda etapa constructiva se finaliza la capilla mayor y las obras avanzan hacia la parte occidental. Este cambio en el proyecto queda patente en la decoración exterior de los aleros. Mientras en los ábsides sur y norte se opta por el uso de arquillos ciegos, en el ábside central se utiliza una decoración con tacos y una serie de canecillos. Esta concepción final de la cabecera ha llevado a Bango primero y a Yzquierdo después, a fechar la segunda fase en torno al $1100^{31}$.

En esta segunda fase se configura también el crucero al que se abren las capillas y se elevan bóvedas y cimborrio. Posiblemente fue en esta segunda etapa cuando se diseñaron la serie de cinco columnas adosadas al muro norte que en su visión actual no soportan nada tras quedar cortadas, presumiblemente ante el cambio final del proyecto ${ }^{32}$. Inmediatamente después, se levantan los complejos y novedosos pilares compuestos que marcan el tránsito entre el crucero y el inicio de las naves. En sus ocho columnas entregas, se encuentran la mayor parte de los capiteles esculpidos del edificio. La importancia y trascendencia de esta intervención desde un punto de vista plástico y arquitectónico llevó a R. Yzquierdo a emplear el nombre de "maestro de San Martiño de Mondoñedo" ${ }^{33}$.

La existencia en una imposta del brazo norte de una inscripción alusiva al obispo Gonzalo se considera prueba, ya desde los trabajos de ViIlaamil34, de que la fábrica hasta el espacio del crucero se elevó durante el obispado de dicho prelado. En su visión actual algunas de las piezas que componen la inscripción están invertidas. Este insólito hecho ha llevado a múltiples interpretaciones. Para M. Castiñeiras las piezas se habrían desmontado y montado de nuevo entre
1865 y 1866 tras el derrumbe del techo de la nave ${ }^{35}$. Sin embargo, R. Yzquierdo sugiere una utilización indeterminada post $1112^{36}$.

Siguiendo de nuevo las conclusiones de este autor, a la muerte del obispo Gonzalo en 1112 se precipitan una serie de acontecimientos que propician la llegada de un tercer taller que finaliza el edificio. Con el traslado de la sede a Valibria en tiempos del obispo Munio Alfonso (1112-1134) se antoja una finalización rápida para el edificio. La llegada de un nuevo taller puede apreciarse claramente en el cambio de planteamientos escultóricos, que en el interior se desarrollan en los capiteles occidentales de los pilares compuestos, y que alcanzan su mayor desarrollo en los canecillos de los muros sur y norte. La iglesia se concluye con la construcción de las naves con unos criterios funcionalistas y mucho más austeros que los empleados en la zona del crucero. La fecha de finalización de las obras no es segura pero se apunta al segundo cuarto del siglo $\mathrm{XI}^{3{ }^{37} \text {. }}$

Esta hipótesis fue aceptada en sus primeros trabajos por M. Castiñeiras ${ }^{38}$, pero en estudios posteriores minimiza la impronta de los talleres que trabajaron en tiempos del traslado de la sede, optando por una valoración más unitaria del edificio y fechando el grueso de las obras en los años 90 del siglo $\mathrm{Xl}^{339}$.

A pesar de las muchas incógnitas por resolver, parece claro que durante el gobierno del obispo Gonzalo, en las dos décadas finales del XI, se eleva la iglesia hasta el inicio de las naves en un lenguaje que aúna la tradición del primer románico y del románico pleno. Posteriormente, en la segunda década del XII, se produce un cambio sustancial en el proyecto que precipita las obras y finaliza con el cierre occidental en el segundo cuarto del XII.

\section{San Martiño de Mondoñedo como yaci- miento arqueológico y su problemática}

Como ya se ha indicado, hasta la fecha se han realizado dos intervenciones arqueológicas en San Martiño de Mondoñedo. La primera tuvo lugar en 1967, y fue dirigida por Manuel Chamoso Lamas, mientras que la segunda se desarrolló cuarenta años después, en 2007, bajo la dirección de Celso Rodríguez Cao y Luis Cordeiro 


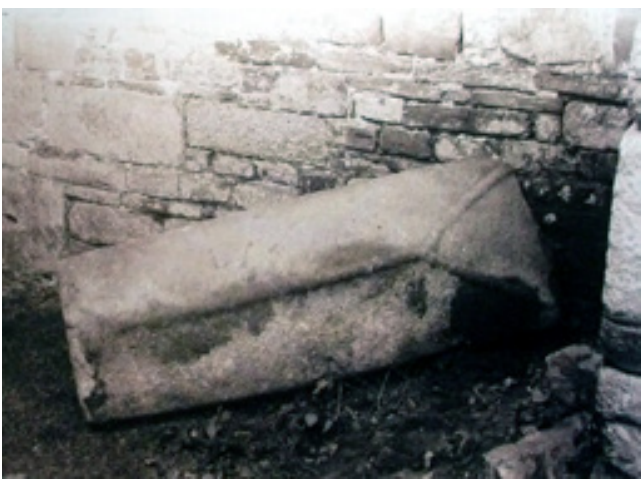

Fig. 2. Tapa de sarcófago con decoración en "estola". Fotografía de M. Chamoso Lamas tomada de V.V.A.A. Lugo no obxectivo de Manuel Chamoso Lamas, Real Academia Gallega de Bellas Artes de Nuestra Señora del Rosario, Lugo, 1995, p. 91

Maañón. Trataremos de realizar un análisis comparativo de la información aportada por ambas excavaciones, teniendo en cuenta la importante diferencia en las metodologías empleadas en una y otra época.

\subsection{La intervención de 1967}

En 1967 Manuel Chamoso Lamas realizó una serie de sondeos arqueológicos en distintos puntos de la basílica y su entorno inmediato ${ }^{40}$. Antes de ello ya había llamado su atención un gran sarcófago de mármol que servía de pilón a la fuente en la huerta de la rectoral, así como otro de granito con tapa de estola descubierto recientemente también en dicha huerta, y que este autor fecha en el siglo VI (fig. 2).

Chamoso excavó en primer lugar en la huerta de la rectoral (antiguo palacio episcopal), al sur de la iglesia de San Martiño. Aunque no proporciona un plano del área estudiada, este autor nos indica que encontraron muros de cimentación asentados en la roca, de unos 90 centímetros de espesor, que avanzaban en dirección noreste y que penetraban bajo las cimentaciones de la actual iglesia, lo que significaría que se trata de alguna construcción más antigua que el actual templo. En la cara exterior de esos muros localizó una serie de sepulturas realizadas con lajas de piedra. Según indica Chamoso, el material recogido en los niveles superiores a las tumbas estaba constituido por fragmentos de ladrillo, ímbrices, cerámica característica de la Alta Edad Media y tres trocitos de "Terra Sigillata"41. No obstante debemos ser cautos a la hora de valorar esta in-
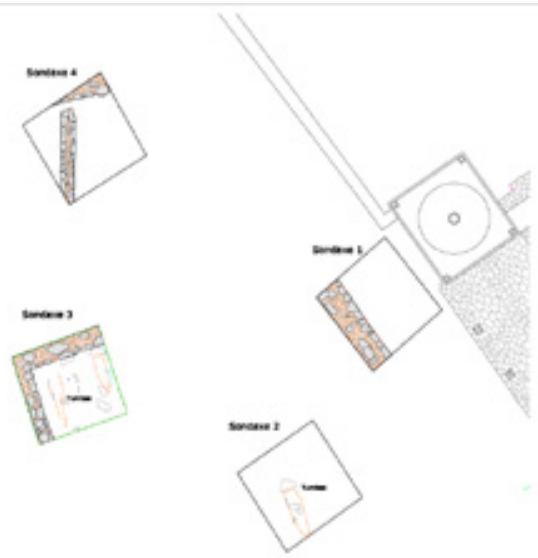

Fig. 3. Localización de los 4 sondeos realizados en 2007 por L. Cordeiro y C. Rodríguez. Plano tomado de L. Cordeiro Maañón, C. Rodríguez Cao, "As sondaxes en San Martiño de Mondoñedo", Bolanda. Cadernos de historia fozega, 2, Mondoñedo, 2010, p. 74

dicación ya que al tratarse de un contexto de enterramientos, la secuencia estratigráfica podría estar alterada tras haber experimentado sucesivas remociones de tierra a lo largo del tiempo. Por otra parte, como ya hemos dicho, no se conservan dibujos de plantas y perfiles que nos permitan observar la estratigrafía y los contextos deposicionales de estos materiales, ni una descripción clara de esta secuencia.

Además Chamoso realizó catas exploratorias en la actual sacristía (cuya arquitectura considera que correspondería originariamente a los siglos IX-X). A unos $60 \mathrm{~cm}$ de profundidad fueron halladas 6 sepulturas dispuestas en dos niveles distintos, cuatro de ellas de lajas con forma antropoide y una de ladrillos, también con forma antropoide. Según indica este arqueólogo, el material asociado a las mismas era cerámica medieval y monedas de bronce ${ }^{42}$. El último sondeo se realizó en el interior del templo, en el ábside menor del lado sur. En él se hallaron restos de un sarcófago de granito destruido al asentar las cimentaciones del templo actual y, a $70 \mathrm{~cm}$ de profundidad, una serie de tumbas antropomorfas de grandes piezas de granito cuidadosamente distribuidas. El material recogido en este sondeo era también cerámica de cronología medieval ${ }^{43}$.

Por último, hay que destacar que en este mismo sondeo se localizó el tercio inferior de una lauda sepulcral escrita en caracteres visigodos 


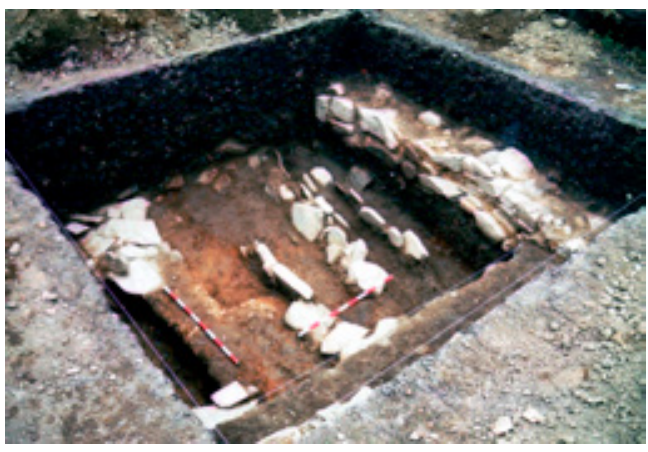

Fig. 4. Vista del sondeo 3 con las estructuras e inhumaciones localizadas en él. Tomado de L. Cordeiro Maañón, C. Rodríguez Cao, "As sondaxes en San Martiño de Mondoñedo", Bolanda. Cadernos de historia fozega, 2, Mondoñedo, 2010, p. 74

distribuidos en dos bandas y bien esculpidos. Aunque Chamoso no ofrece cronologías para la misma, Manuel Núñez Rodríguez, años más tarde, apuntó el gran parecido de algunos de sus tipos con los de la inscripción documentada en Santa Eufemia de Ambía, datable en torno al siglo X. Pese a que no ha sido posible transcribir su contenido, la vincula con la nueva obra realizada por San Rosendo en el año 928 tras el ataque musulmán de $870^{44}$.

Chamoso Lamas interpretó todos estos hallazgos arqueológicos de "importantes cimentaciones" y necrópolis a ellas asociadas como evidencias del "monasterio Maximi" del siglo VI, mencionado en el Parroquial Suevo como parte de la sede de Britonia.

\subsection{Los sondeos de 2007}

En 2007 Celso Rodríguez Cao y Luis Cordeiro Maañón realizaron distintos sondeos arqueológicos tanto en la huerta de la casa rectoral como en la sacristía, al igual que Chamoso había hecho 40 años antes. Poco antes de su excavación, durante la rehabilitación de la casa rectoral, se produjo el hallazgo de dos sepulturas antropomorfas excavadas en la roca ${ }^{45}$. Estos arqueólogos realizaron cuatro sondeos de $4 \times 4$ metros cada uno en la huerta $^{46}$ (fig. 3). En ellos fueron detectadas dos estructuras que seguían una orientación paralela al muro sur de la iglesia (la cimentación de un muro y una alineación de piedras que podría constituir el suelo de acceso a la puerta de la torre) así como otros muros de orientación diferente a la iglesia, de 60 centímetros de ancho.

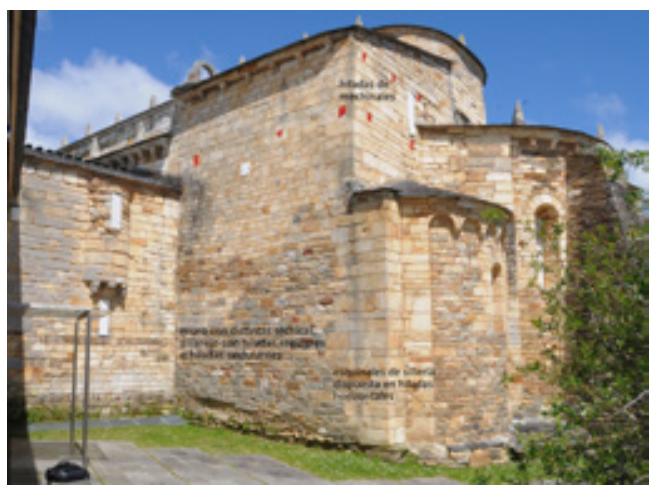

Fig. 5. Cabecera y esquinal del lado sur. Imagen de los autores

Estos autores consideran que estas estructuras podrían datarse, como la basílica, a fines del siglo XI o inicios del XII, y podrían corresponder al conjunto de dependencias que formaban el antiguo complejo episcopal, quizá el claustro y dependencias de los canónigos de San Agustín asentados en San Martiño desde 1133.

Por debajo del nivel de estas estructuras localizaron un total de 8 sepulturas, de distinto tipo: una sepultura en fosa antropomorfa excavada en roca y cubierta de granito, la más antigua y quizá fechable en el siglo $X$, otra sepultura con lajas y forma antropomorfa y varias tumbas de arco de paréntesis, todas ellas encuadrables entre los siglos X-XI (fig. 4). Según estos autores se trataría, por tanto, de parte de una necrópolis más extensa que se dataría en el momento de transición del edificio prerrománico al románico, entre los siglos $\mathrm{X}$ y $\mathrm{Xl}^{147}$.

En cuanto a su intervención en la sacristía, constataron que, frente a la idea de que este espacio tenía su origen en los siglos X-XI, en realidad debió de hacerse poco después de acabar la iglesia románica, en la primera mitad del siglo XII, sin que haya evidencias de que esta construcción naciese de otra anterior prerrománica ${ }^{48}$. En la cimentación, en un revestimiento de época contemporánea, localizaron un ladrillo, que por sus características podría ser romano (existiendo otro similar en el ábside, también de una reconstrucción reciente). Por debajo se hallaron dos sepulturas, anteriores a la capilla. Se trata de dos tumbas trapezoidales, hechas de lajas y con orejeras en su cabecera. Ambas están colmatadas 


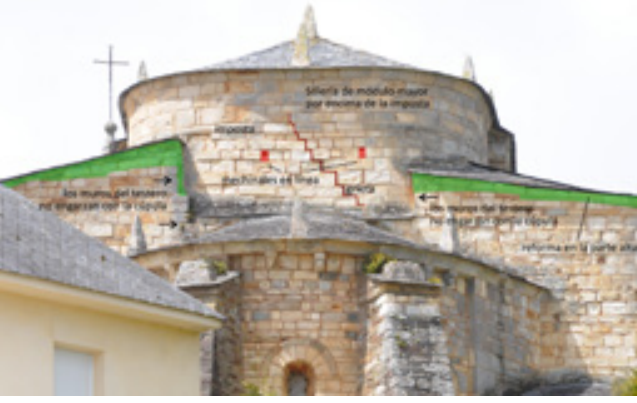

Fig. 6. Parte superior de la cabecera. Fotografía de los autores por la intervención de Chamoso y podrían datarse entre mitad del XI e inicios del XII ${ }^{49}$.

3.3. Algunas reflexiones sobre el contexto arqueológico de San Martiño

Al comparar ambas excavaciones, la de 1967 y 2007, encontramos ciertas incoherencias que nos conducen a una serie de reflexiones. De hecho ya Celso Rodríguez y Luis Cordeiro expresan sus cautelas y dudas, por lo menos con respecto a la existencia de estructuras del siglo $\mathrm{VI}$, tal y como planteaba Chamoso, recordando que su metodología de excavación era muy diferente a la que se emplea actualmente, y consideran necesarios nuevos estudios para aclarar este aspecto. Para estos autores las fases arqueológicas que sí están claras en San Martiño de Mondoñedo se encuadrarían entre los siglos IX y XII, teniendo en cuenta los materiales recuperados y la tipología de las tumbas ${ }^{50}$. También Arias Vilas considera más probable que los restos detectados por Chamoso correspondan a los siglos IX-X que a períodos anteriores ${ }^{51}$.

En efecto, Chamoso consideraba que las cimentaciones y la necrópolis documentada en torno a ellas corresponderían al "monasterio Maximi" del siglo VI, que sería destruido en el siglo IX por los ataques árabes. Sin embargo, llama la atención que en los cuatro sondeos de 2007, realizados en el mismo espacio de la huerta de la rectoral en el que había intervenido Chamoso cuarenta años antes, no se identifiquen niveles más antiguos que la necrópolis de los siglos IX-XI, correspondiendo las estructuras detectadas a los siglos XI-XII. Además, hay que subrayar que las tumbas halladas en 2007 son del mismo tipo (lajas) que las detectadas por Chamoso y que él asociaba al periodo tardoanti-

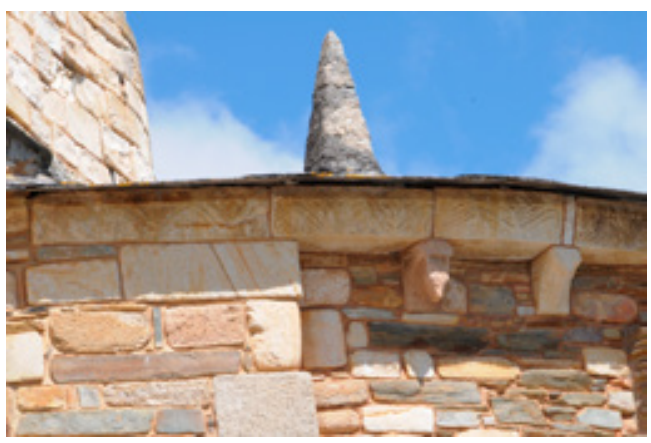

Fig. 7. Fragmentos de frisos reutilizados en el alero de la cabecera. Fotografía de los autores

guo. Es decir, parece que coincide la estratigrafía y la tipología de las estructuras documentadas, pero no así las interpretaciones de ambas. Otro de los elementos en los que se basa Chamoso para hablar de una etapa del siglo VI en este lugar es la aparición de una tumba con tapa de "estola". Sin embargo, sabemos por las últimas revisiones que este tipo de tumbas pueden perdurar hasta el siglo $X^{52}$.

Cabe pues plantearse si la interpretación de Chamoso es errónea y las evidencias que él consideraba de los siglos VI-IX son realmente las estructuras y necrópolis de los siglos IX al XII. Es cierto que desconocemos la ubicación exacta de los sondeos de Chamoso, pero las catas de 2007 documentaron la remoción de tierras derivadas de aquellos, con lo cual por lo menos ambas intervenciones se debieron solapar parcialmente. Es igualmente cierto que, según Chamoso, las estructuras documentadas en la huerta continuaban bajo la iglesia actual, de modo que serían más antiguas que ésta. No obstante, aun siendo esta apreciación cierta, dichas estructuras podrían pertenecer a la iglesia o dependencias del conjunto episcopal del siglo $X$, más que a un hipotético y problemático horizonte del siglo $\mathrm{VI}$, ya que no ha sido documentado arqueológicamente.

\section{Una aproximación arqueológica a la fá- brica de San Martiño}

Todos los autores que han estudiado San Martiño coinciden en señalar que conserva elementos de distintas fases, especialmente de la etapa prerrománica (entendidos, literalmente, como la anterior a la actual y principal fase románica). Sin 


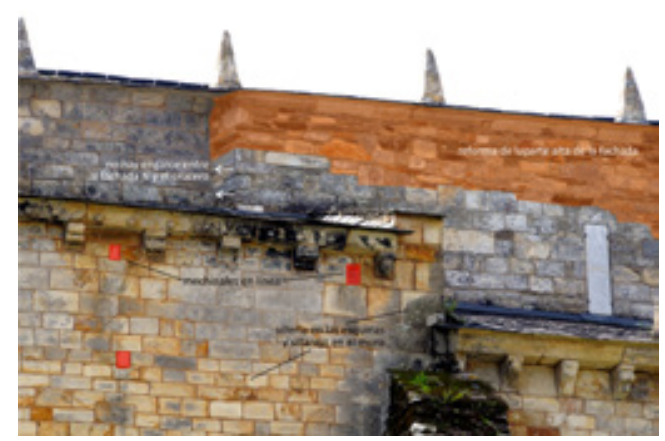

Fig. 8. Vista del engarce entre la cabecera y la fachada norte de la iglesia. Imagen de los autores

embargo, existen ciertas divergencias entre ellos con respecto a cuáles son dichos elementos, cuál es su ubicación exacta en la fábrica y cuál sería su cronología. En este apartado realizaremos un nuevo acercamiento a esta cuestión a partir de una aproximación arqueológica a su arquitectura. Debemos subrayar que no se trata de una lectura exhaustiva de los paramentos de este edificio (lo que sería propiamente un análisis estratigráfico de paramentos), algo necesario para ofrecer conclusiones sólidas sobre la secuencia constructiva de esta iglesia, pero que escapa de las posibilidades actuales de este trabajo. Lo que proponemos es una primera y preliminar valoración general del edificio basada en la observación de sus paramentos con el fin de identificar posibles diferencias de aparejos y técnicas constructivas así como la existencia de interfaces que puedan indicar distintas épocas constructivas. Los resultados, por tanto, deben considerarse como simples vías de trabajo, a la espera de una completa lectura estratigráfica de este edificio.

Uno de los aspectos que caracteriza las fábricas de San Martiño es la heterogeneidad de tamaños y colores de los materiales constructivos empleados. Sin embargo, precisamente en base al mantenimiento de esta heterogeneidad en la práctica totalidad de los muros, se puede apreciar una homogeneidad en muchas zonas del edificio. En ese sentido, como explicaremos a continuación, parece que existe una fábrica medieval unitaria en la zona de la nave norte, la nave central (excepto la parte alta que sería una reforma posterior), el crucero, los ábsides, los hastiales, e incluso lo poco que se puede ver actualmente de la zona sur (que también presenta una refor- ma en altura). A esa heterogeneidad parece que contribuye la posible reutilización de piezas, tal vez procedentes del edificio prerrománico, y el empleo de materiales geológicos dispares acorde con un gusto estético que se documenta también en otros edificios probablemente coetáneos como San Antolín de Toques.

\subsection{La cabecera y el crucero}

Parece claro que la cabecera es unitaria (con la excepción de la parte alta de la cúpula y una reparación puntual en altura de los hastiales del crucero), porque hay un indicador cronológico para ello: dos hiladas de mechinales, es decir, los huecos que se abren en la pared para disponer los pontones de los andamios. Cuando unos mechinales recorren en la misma hilada un muro, podemos pensar de que este muro es unitario pues implican que todo ese sector se construyó en un mismo momento (figs. 5 y 6). Sin embargo, llama la atención la parte alta de la cúpula desde la imposta ya que presenta un aparejo más cuidado, de sillería regular de un módulo ligeramente mayor, lo que da la impresión de que las 4 últimas hiladas de la cúpula son posteriores, y que se levantan sobre una hilada de regularización. También llama la atención la diferente altura de los brazos norte y sur el crucero, y el engarce de la nave central con esta parte alta de la bóveda, así como el engarce de los hastiales del crucero con el tambor de la cúpula. Los engarces con la cúpula no están bien resueltos, lo que se puede deber a que correspondan a dos fases o a que, por ser un modelo muy temprano, aún no sepan resolver esa solución de continuidad entre diferentes cuerpos (fig. 6). En el muro Sur del crucero también se aprecia alguna irregularidad, pero probablemente se trate de alguna pieza repuesta a posteriori, que se mezcla con esa forma de construir heterogénea y con una unión con el ábside bastante irregular. En todo caso, esto no explica la distinta altura de los brazos del crucero.

Los problemas en las uniones son generales al edificio y podemos pensar que es una cuestión de tipo constructivo. No debemos olvidar que nos movemos en un románico temprano para el Noroeste peninsular, en el que se están ensayando soluciones para estas zonas, los encajes entre distintos cuerpos, que suelen ser las más proble- 


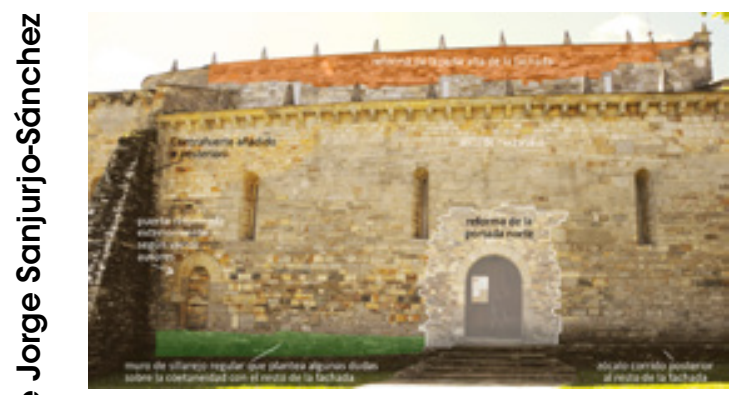

Fig. 9. Análisis de la fachada norte. Imagen de los autores

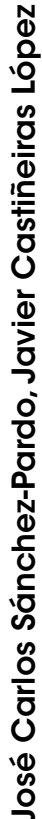

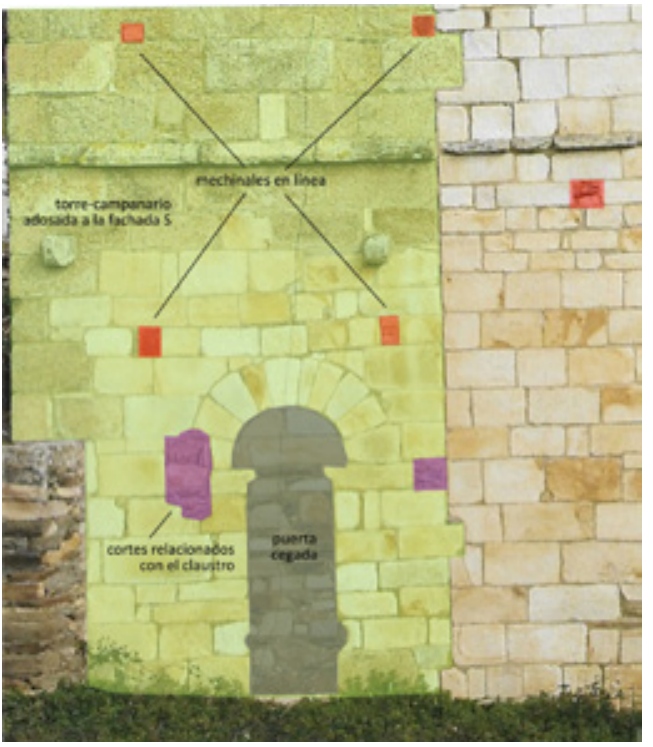

Fig. 10. Parte inferior del lado sur de la torre. Imagen de los autores a partir de la fotografía de M. A. Castiñeiras González,

"San Martiño de Mondoñedo (Foz) revisitado", p. 120

máticas de un edificio. En ellas usan piezas más grandes dispuestas a soga y tizón, contrastando con el aparejo del resto del muro, en el que se emplean sillares de menor tamaño (normalmente sillarejos), las hiladas ondulan, doblan y los materiales son más heterogéneos. Para la parte alta de la cúpula se reserva, sin embargo, un aparejo similar a las esquinas, lo que nos hace dudar de la hipótesis de que correspondan a dos fases constructivas. A pesar de esta irregularidad, nuevamente, si observamos la parte alta del crucero sur, vemos cómo la doble línea de mechinales se abre tanto en el muro como en la esquina, reforzando su unidad (fig. 5).
También cabe destacar la reutilización de fragmentos de friso en alero del ábside central, que según Núñez e Yzquierdo provienen del antiguo alero de la iglesia prerrománica, ya que presenta formas de herencia visigoda, como los tallos ondulados con temática de hojas y flores de cinco pétalos, que se relacionarían con los prototipos de Peñalba ${ }^{53}$ (fig. 7). Para Yzquierdo es evidente que dichas piezas son prerrománicas, debido a su labra y a que no fueron preparadas para estar en el lugar actual ya que tuvieron que intercalarse pequeños fragmentos lisos de piedra entre ellas, y aun así no cubren todo el contorno del ábside, faltando en el extremo sur. Además, este autor añade que quizá también sea del período prerrománico una pieza reutilizada en el cierre del baptisterio que presenta en dos de sus lados un tallo ondulante con hojas alternadas como la celosía de San Xés de Francelos y otras del arte asturiano ${ }^{54}$. Aunque cree que no hay paralelos claros en Galicia para estas piezas, piensa que se aproximan a ciertas celosías del prerrománico asturiano así que su cronología no superaría el s. IX ${ }^{55}$

\subsection{Muro exterior norte}

Según Núñez, el muro norte todavía preserva algunas hiladas del aparejo prerrománico así como restos de un arco en herradura de una antigua puerta, que habría sido en origen muy similar a la de San Martiño de Pazó (Allariz, Ourense). Esta puerta se encontraría hoy alterada por retoques de época románica como la disposición de una moldura ajedrezada sobre ella y la pérdida de las dovelas que finalizaban el arco en herradura56. Castiñeiras secunda estas ideas de Núñez sobre los restos prerromanicos del muro norte ${ }^{57}$, mientras que Yzquierdo no se pronuncia sobre ellos (sí lo hace, sin embargo, en relación al muro sur, lo que parece indicar algún tipo de reserva sobre esta interpretación). De hecho, Núñez considera que las cinco columnas, sin capitel, engarzadas en el interior del muro norte, podrían ser vestigios de antiguos soportes prerrománicos, como los de Santa Cristina de Lena, es decir, propios de una iglesia de nave única con semicolumnas entregas organizadas en tambores ${ }^{58}$, mientras que Yzquierdo cree que estos tambores provienen de un primer proyecto de época románica que habría sido sustituido por otro quizá a inicios del siglo XII59. 
Sin embargo, nuevamente la observación de la existencia de mechinales en línea, presentes a lo largo de todo el muro exterior de la nave, nos pone en la pista de una única fase constructiva principal para este lateral de la iglesia, con la excepción de una reforma para la apertura o reforma de la actual puerta principal. La puerta cegada es coetánea a dicha fábrica, al margen de que pudiera estar o no realizada con material reutilizado de un antiguo arco de herradura prerrománico; pero no se observan elementos en ésta que recuerden a un arco de herradura y los engarces con el muro están perfectamente ejecutados. Además, esta puerta es tipológicamente igual que las ventanas de la cabecera (aceptadas como románicas). Por otro lado, las partes altas de la nave central son claramente posteriores, quizá de la reforma que menciona Castiñeiras; en ellas se usa un aparejo similar al de la reforma de la actual puerta lateral (figs. 8 y 9).

La única duda se plantea en la parte baja, bajo la puerta cegada. En esta zona se documenta un aparejo (sillarejo) muy similar al de San Martiño de Pazó, y que, dada su posición estratigráfica, sí podría pertenecer a una hipotética fábrica prerrománica. Sin embargo, este mismo aparejo es muy similar al empleado en otras zonas de la misma fachada, con la única diferencia de que el material, un granito gris, es unitario mientras que en el resto se mezclan materiales distintos (con diferente coloración) y en algunas zonas tienen un despiece heterogéneo (doblando, inclinando u ondulando hiladas). Creemos que esta heterogeneidad de los materiales y aparejo de San Martiño es la que provoca la sensación de la coexistencia de distintas fases constructivas. Se trata de una forma de aparejar que se observa también en San Martiño de Pazó donde se alterna el tamaño y forma de los materiales pero se emplea el mismo material, y en San Antolín de Toques donde conviven hiladas de diferente altura, sillería y sillarejo, y se emplean materiales distintos, produciendo un efecto en el muro como si se tratara de un mosaico. Además hay que tener en cuenta que esta zona se encuentra a nivel de cimentación, es decir, toda la parte norte y este de San Martiño está descarnada, dejando la cimentación a la vista, ya que el nivel del suelo está sobrepasado, como se puede ver por la puerta cegada sobreelevada, cuyo alféizar estaría a la altura del de la actual puerta de entrada. Quizá la ausencia de heterogeneidad de colores en la piedra se deba precisamente a que esta zona no estaba pensada para ser vista, sino para estar bajo tierra. En todo caso, sólo una lectura estratigráfica completa del edificio y, tal vez, la datación de los morteros, permitiría salir de dudas.

\subsection{Muro exterior sur}

Los estudios previos también han incidido en la presencia de restos prerrománicos en el muro sur. Núñez cree que en este muro también se ve gran parte del aparejo prerrománico ${ }^{60}$, algo que también afirman Castiñeiras - quien habla de técnica constructiva propia del siglo $X$, con hileras de aparejo a soga y tizón, similares al alzado de Pazó61-, e Yzquierdo, para el cual la parte baja del muro sur sería parte de un antiguo muro prerrománico del siglo $X$ reutilizado en la construcción románica, aunque matiza que es difícil definir al detalle sus partes ${ }^{62}$.

Resulta difícil valorar este muro debido a la imposibilidad de acceder al patio de la huerta rectoral durante nuestras investigaciones. Es evidente que hay distintos tipos de aparejo en él así como huellas de reformas puntuales, correspondientes éstas últimas a distintas fases constructivas. Sin embargo, la línea de mechinales situada por encima de los arcos de las ventanas, visible a lo largo de toda la nave, nos pone de nuevo en la pista de una fábrica en general unitaria. Además, las hiladas se mantienen pese al cambio de aparejo. En este caso, se está empleando una técnica muy similar a San Martiño de Pazó (iglesia datada en el siglo $X)$ y que ya hemos documentado y descrito en el muro $S$ del crucero: sillería a soga y tizón en las esquinas con sillares bastante regulares y una alternancia de sillarejo y sillería en el muro, con algunas hiladas ondulantes y que doblan. Se trata de una fábrica similar a la documentada en el muro norte, aunque a diferencia de aqueIla, en el muro sur se emplean en la parte baja materiales heterogéneos y en la media y alta el mismo material. También llama la atención que el remate de las ventanas de este muro sur es diferente a las del muro norte. Todo esto (la diferencia de alternancia y el distinto remate de las ventanas), podría llevar a pensar que estamos ante dos fases distintas o ante un cambio de proyecto como propone Yzquierdo63, pero sería 


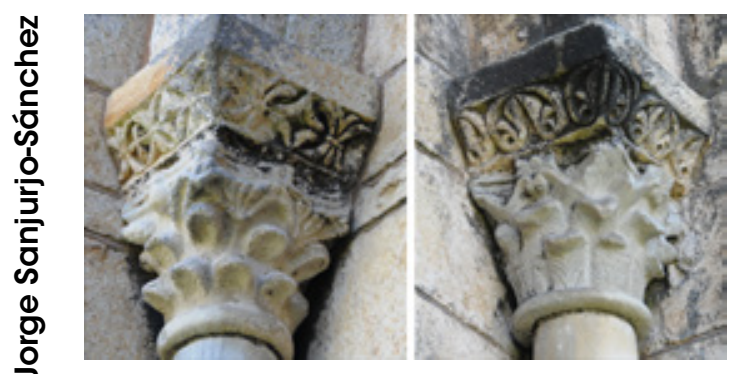

Fig. 11. Capiteles reutilizados a ambos lados de la puerta principal de la basílica. Fotografía de los autores

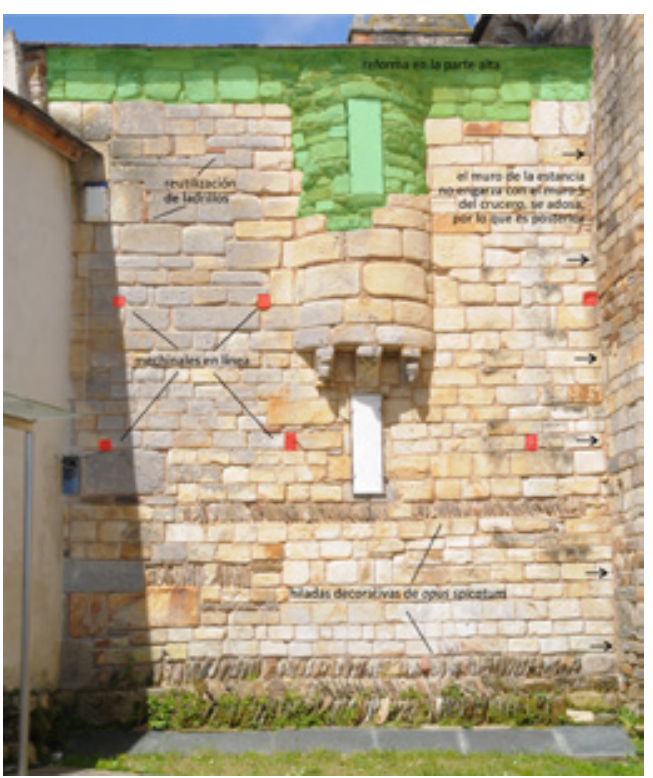

Fig. 12. Análisis de la fachada Este de la sacristía. Imagen de los autores

necesario llevar a cabo un estudio más exhaustivo de la fábrica, sobre todo en el muro sur, que nos permita determinar la secuencia constructiva con mayor exactitud, más allá de la aproximación que hacemos en este texto. De hecho, esta fachada es la que parece contar con un mayor número de intervenciones posteriores; en ella se aprecia una reforma en altura que corta lo que parece la losa de remate de una cubierta a un agua de una de las pandas del claustro, se observa una línea de grandes mechinales para vigas tapiados, otra línea de ménsulas, la apertura y cierre posterior de una puerta adintelada así como el encastramiento de la torre oeste al muro sur.
A primera vista la torre parece presentar dos fases, ya que se emplean dos tipos de materiales, uno similar al utilizado en el muro sur de la nave, y otro de sillería de granito; sin embargo, tras un análisis más detenido, no creemos que se trate de un aparejo diferente, la manera de engarzar la torre con el muro sur es igual en ambas zonas, y se trata de una sillería de iguales características. Caben pues, dos posibilidades: o bien se está reutilizando material procedente de la construcción de la iglesia a la que pertenece la nave sur, o bien están aprovechando un muro anterior como base para la torre, imitando su aparejo. En todo caso, ese muro sería posterior a la nave ya que nos encontramos una interfaz entre ambas y el engarce en la parte baja (fig. 10). Esta torre merecería una lectura en detalle, ya que sus otras fachadas presentan una técnica constructiva distinta y un tipo de ventanas diferentes; mientras en el muro sur se conserva una saetera, en el oeste se abre una ventana geminada que, a su vez, corta una ventana anterior de la que se aprecian parte de las dovelas que la remataban, de un modo similar a las de la fachada norte.

Por último cabe señalar que Núñez, secundado por Castiñeiras, indica que el muro sur aun conservaría dos pequeñas ventanas saeteras (diferentes del resto de ventanas románicas) con arco en herradura descentrada que seguirían un estilo mozárabe ${ }^{64}$. Yzquierdo apoya esta idea (aunque presenta sus dudas con respecto a la saetera más occidental), y añade que encima de ambas saeteras existen unos curiosos sillares con perfil en forma de T que, al igual que otro reutilizado en el muro oriental de la sacristía, evocan las claves de los arcos de Santa María del Naranco, por lo que serían una solución genuina del arte prerrománico de mitad del siglo IX, momento en que se establece por decisión real la nueva diócesis de Mondoñedo en San Martiño65. También Núñez y Castiñeiras hablan de un arco prerrománico que habría sido desmontado y trasladado de su primitivo emplazamiento a la base de la torre. Este arco solo conservaría ya seis dovelas prerrománicas y habría tenido forma de herradura inicialmente, similar al de San Martiño de Pazó6, pero, al igual que sucede en la fachada norte, o en las ventanas de la sur, no apreciamos en la actualidad ningún indicio de estos arcos de herradura. 


\subsection{Portada occidental}

La fachada occidental también parece en su mayor parte unitaria, engarzando coherentemente con el lado norte. Añadidos posteriores, además obviamente de los contrafuertes, serían algunas reformas en la parte superior y la torre, que se adosa a la fachada. Por su parte, los dos capiteles corintios de granito más próximos a la puerta principal y que descansan sobre columnas de mármol fragmentadas, parecen reutilizados (fig. 11). Chamoso consideraba que estos capiteles serían "de época romano-tardía, más bien propios del siglo VI, de época sueva o visigoda"67, al igual que opinaba Regal68. En cambio Núñez considera que el de la jamba izquierda se aproxima a una tipología hispanovisigoda, mientras que el de la derecha posee una concepción más gráfica, con hojas pegadas directamente al fondo, y una decoración incisa de talla próxima a modelos leoneses del siglo $X$ como los de Santiago de Peñalba ${ }^{69}$. En todo caso, ambos provendrían del antiguo edificio prerrománico, al igual que otro que sirve de pila bautismal en el interior del templo que también sería "prerrománico", ideas que secunda Yzquierdo ${ }^{70}$. También Castiñeiras sigue estas opiniones, matizando que el segundo capitel podría datarse hacia el año 940, en relación con el edificio de San Rosendo, mientras que el izquierdo se vincularía al período suevo o visigodo y habría sido también reutilizado en época de Rosendo ${ }^{71}$.

Concordamos con estos autores en la filiación típicamente altomedieval de ambos capiteles y sus fustes. Los fustes, y quizá el capitel izquierdo, podrían ser ya reutilizados en el edificio altomedieval, ya que se trata de un elemento de expolio habitualmente requerido en la Alta Edad Media72. Por otro lado, cabe señalar que el capitel de la jamba izquierda presenta cierto parecido con el conservado en una de las columnas recolocadas en la cripta de Santa Eulalia de Bóveda (Lugo). Además de estas piezas, R. Yzquierdo cree que también podría ser del siglo $X$ el bajorrelieve con una cruz griega (típica, aunque no exclusiva, de la monarquía asturiana) colocado encima de la ventana abierta sobre la portada. Aunque hoy es casi imperceptible, a fines del s. XIX, se veían en esa zona varias inscripciones en las que Villaamil pudo leer "DOMVN/AEDIFICAVIT/A ASLU"7з.

\subsection{Sacristía}

Chamoso Lamas consideraba que el edificio de la sacristía sería una construcción prerrománica74. Aunque Yzquierdo en 1993 indica que se trataría de un edificio posterior a la construcción de la basílica románica75, en su artículo de 2007 parece admitir que la sacristía podría ser prerrománica, como creía Chamoso ${ }^{76}$. En este cambio de opinión parece haber influido el trabajo de Castiñeiras, para quien la actual sacristía, de dos pisos, tendría su origen en época de San Rosendo, dada su planta rectangular y la baja bóveda de cañón del nivel inferior con vanos cuadrangulares que recuerdan a la Cámara Santa de Oviedo (cuya estancia superior está igualmente dedicada a San Miguel) y a estancias similares en Valdediós y en Tuñón. Aunque el edificio habría sufrido una reconstrucción en época románica, este autor considera que todavía mantiene su aparejo original prerrománico, a soga y tizón (como en San Martiño de Pazó y en San Miguel de (elanova) en el muro que da a las naves, en la pared occidental o en la fachada sur. Para Castiñeiras, la dedicación de un altar a San Miguel coincidiría con la de Celanova, erigido por Froila, hermano de Rosendo. La función funeraria de San Miguel explicaría el uso como cementerio de este tipo de capillas ${ }^{77}$.

Sin embargo, frente a estas posiciones, consideramos que la sacristía es unitaria excepto una reforma con mampostería regular en la parte alta. Por lo que podemos apreciar en el muro este exterior, el aparejo no presenta cortes, tratándose de hiladas continuas con algún codo y desdoblamiento. Las esquinas son de sillería a soga y tizón y el muro de sillería y sillarejo alternando con hiladas regulares de opus spicatum que claramente forman parte del muro. Apenas se aprecia alguna irregularidad en el engarce con el muro de la saetera y el cuerpo semicircular de la plata alta, que se apoya sobre canecillos reutilizados a modo de ménsulas. Además, las hiladas de mechinales son regulares, como sucede en el cuerpo de la iglesia. También es interesante señalar que en este muro hay un sillar en T como los de las ventanas de la fachada sur.

La capilla está claramente adosada el muro sur de la iglesia, ya que no traba con ésta, por lo que es posterior (aspecto que ya proponen Cordeiro y Rodríguez) ${ }^{78}$. Consideramos que el aparejo 
de opus spicatum es un recurso decorativo, pero no una preexistencia, ya que por debajo hay una cimentación similar a la del crucero sur de la iglesia (fig. 12), por encima un aparejo similar al de la iglesia, y más arriba se repite el spicatum. Parece tratarse de en un momento de transición, con un gusto por lo heterogéneo. Los ladrillos en la cimentación son reutilizados, como los que hay por toda la iglesia, e incluso en otras partes altas de esta misma estancia. Concordamos en este sentido con Cordeiro y Rodríguez, quienes en base también a una apreciación de los paramentos, creen que la sacristía debió hacerse una vez terminada la basílica románica, probablemente entre el primer tercio y la mitad del siglo XII79.

\section{Datación de la cúpula}

\subsection{Obtención de las muestras}

Durante las intervenciones llevadas a cabo en 2007 con motivo de la restauración de las pinturas de la cúpula de San Martiño por parte de un equipo dirigido por Blanca Besteiro, se detectaron debajo de estas, unos tubos machihembrados de cerámica que horadaban la misma y que habían sido tapados con madera, recubiertos de mortero con el resto de la cúpula y pintados. Este tipo de elementos no son habituales en este tipo de cúpulas, por lo que la Xunta de Galicia decidió encargar una serie de análisis para datar la bóveda y los elementos documentados. En ese contexto, se recogieron dos muestras de ladrillo y dos de mortero de la cúpula, así como madera que taponaba los tubos. También se tomó una muestra de mortero y ladrillo del tambor de la cúpula en el lado sur, a una altura de $2 \mathrm{~m}$. Dado que apenas existen ladrillos en esa zona se sospechaba que podría tratarse de ladrillos reutilizados, lo que en luminiscencia proporciona fechas sobreestimadas. Sin embargo, los morteros no son reutilizables, por lo que representa un material ideal para datar estructuras ${ }^{80}$.

\subsection{Datación por luminiscencia}

Los métodos de datación absoluta permiten obtener edades a partir de materiales arqueológicos. La datación por luminiscencia es uno de los métodos más usados en arqueología y en los últimos años se ha revelado como la técnica que mejor resultado da a la hora de fechar ladrillos y morteros ${ }^{81}$. Se basa en los efectos causados por la radiación ambiental en minerales contenidos en los materiales objeto de estudio ${ }^{82}$. La ventaja de datar morteros frente a ladrillos estriba en que los morteros no son reutilizables, por lo que fechan la construcción y no la manufactura de un material que puede ser reutilizado ${ }^{83}$.

La ecuación de edad de luminiscencia es el cociente entre la dosis recibida (estimada por análisis por luminiscencia como dosis equivalente o De) y la tasa de radiación ambiental (conocida también como tasa de dosis o DR). Por lo que analizando ambos, se obtiene la edad. Para obtener la dosis recibida se usa la luminiscencia y para la tasa de radiación se mide la composición en isótopos radiactivos de potasio, uranio y torio de los materiales estudiados y de su entorno.

\subsection{Análisis de muestras}

La muestra de madera fue enviada al laboratorio de datación por AMS de la Universidad de Uppsala (Suecia) para su datación por ${ }^{14} \mathrm{C}$. Tanto para las muestras de ladrillo como para las de mortero se realizaron dataciones por luminiscencia en el Laboratorio de la Universidad de A Coruña. Todas las muestras fueron analizadas por Espectrometría de Masas por Acoplamiento de Plasma Inducido (ICP-MS) en el CACTI de la Universidad de Vigo, para estimar la tasa de radiación. Para obtener las tasas de radiación se estimaron las DR beta y gamma utilizando los factores de conversión de Guerin et al. y aplicando los cálculos de estimación de la DR cósmica propuestos por Prescott y Hutton ${ }^{84}$.

Para la datación se aplicó un protocolo de preparación de cuarzo de grano grueso ${ }^{85}$ y se realizaron medidas de luminiscencia en un lector automático RIS $\varnothing$ TL/OSL-DA-15 equipado con un fotomultiplicador EMI 9635 QA, y utilizando un filtro Hoya U-340. El equipo consta de una fuente beta interna de ${ }^{0} \mathrm{Sr} /{ }^{\circ} \mathrm{Y}$ que proporciona una dosis de $0.130 \pm 0.004 \mathrm{~Gy} / \mathrm{s}$. Para los morteros se utilizó OSL (luminiscencia ópticamente estimulada) ${ }^{86}$ mientras que para los ladrillos se utilizó la técnica de OSL y también la de TL (termoluminiscencia ${ }^{87}$. En morteros, para calcular las edades se utilizó el modelo de Edad Central (CAM), propuesto por Galbraith et al. ${ }^{88}$, dado que las alícuotas analizadas indicaban distribuciones unimodales, mientras que para la muestra SMF-M1 se usó el 
modelo de edad mínima (MAM) propuesto por los mismos autores al tratarse de una muestras con distribuciones de alícuotas multimodales para la dosis equivalente.

\subsection{Resultados}

Los datos de concentración de U, Th y K obtenidos para las muestras permiten obtener la dosis anual (DR) para todas ellas y se detallan en la tabla 1. A partir de estos datos se han obtenido las DRs estimadas, siendo la suma de la DR beta, DR gamma y DR cósmica. La tabla 2 detalla cada DR y la DR final para cada muestra (Anexo: tablas 1 y 2 ).

Para la muestra SMF-M3, correspondiente al muro no se pudo obtener cuarzo puro y se testó una muestra de cuarzo y feldespato pero no se pudo obtener una edad. La señal de luminiscencia de todas las muestras, excepto la SMF-M3, es de buena calidad, con una alta relación señal/ fondo. En la OSL, esta relación proporciona una estimación de dosis con bajo error. La estimación de las EDs proporcionaba resultados notablemente más bajos para los morteros que para los ladrillos, siendo en todos ellos similares y rondando los ladrillos 4Gy de ED mientras que los morteros rondaban $1 \mathrm{~Gy}$ de ED. Los resultados se muestran en la tabla 3 (Anexo: tabla 3).

Las EDs obtenidas por TL y OSL para los ladrillos eran completamente coincidentes. Considerando la dispersión de las muestras a través del valor de sobredispersión, propuesto por Galbraith et al. (1999) se selecciona el modelo de edad más adecuado para cada muestra ${ }^{89}$. En el caso de la muestra SMF-M1 el modelo aplicado es el MAM (modelo de edad mínima) al haber una sobredispersión elevada, mientras que para la muestra SMF-M2 se aplicó el CAM (modelo de edad central) por la baja sobredispersión, si bien, para esta muestra, el número de alícuotas medido es bajo. A partir de los datos de ED y DR se calcularon las edades (Anexo: tabla 4). En el caso de los ladrillos, se seleccionó la estimación de ED obtenida por OSL al proporcionar una mayor precisión.

Como puede observarse, la edad de los ladrillos es notablemente superior a la de los morteros. Una cuestión de interés es que la edad de los ladrillos es relativamente coincidente, situándose aproximadamente entre el siglo III y el VII. Como se ha comentado anteriormente, los ladrillos pueden ser reutilizados ${ }^{90}$, por lo que se considera más fiable datar los morteros, que son preparados para el momento de construcción de una estructura91. Por ello, la edad obtenida para los ladrillos solamente indica que son reutilizados y más antiguos que la estructura estudiada, probablemente en al menos más de un siglo. Por ello, la edad representativa de la cúpula de San Martiño es la obtenida a partir de los morteros. Aunque la muestra SMF-M2 presenta menos error que la SMF-M1, su resultado no es estadísticamente representativo por sí sólo, ya que se basa tan solo en 10 alícuotas, cuando en luminiscencia suelen requerirse al menos el doble. Por eso, el resultado más fiable es el de la muestra SMF-M1, pese a que presenta un margen de error elevado (del $30 \%$ ), debido al uso del MAM a partir de un número pequeño de las alícuotas cuyo error era relativamente elevado. Este resultado indica que la cúpula debió construirse en torno al siglo XII, confirmando las hipótesis tradicionalmente planteadas desde la historia del arte para este edificio. Por último, como se observa, el fragmento de madera corresponde a un añadido posterior, en un momento situado entre el final del siglo XV y la primera mitad del siglo XVII, lo que podría corresponder a la época de última intervención en la bóveda e incluso ser coetánea a las pinturas.

\section{Conclusiones}

A lo largo de las páginas previas hemos realizado una revisión crítica de la información, tanto arqueológica como histórico-artística, sobre San Martiño de Mondoñedo, que nos ha aportado nuevos datos para continuar estudiando este emblemático edificio.

En primer lugar, la revisión de la información sobre los restos arqueológicos documentados en el subsuelo de San Martiño ha mostrado que las evidencias de la existencia de un posible edificio del siglo VI en este lugar, tal y como pretendía Chamoso Lamas, son muy débiles. De hecho, desde el punto de vista del registro material disponible, tan sólo se puede constatar una ocupación arqueológica segura de este lugar desde los siglos IX-X.

El análisis de los paramentos conservados revela que, frente a las ideas tradicionalmente sos- 
tenidas, la mayor parte de la fábrica del edificio es unitaria, a excepción de la zona alta de unión entre el ábside y la nave, que presentan algunas alteraciones, irregularidades y discontinuidades que podrían pertenecer a dos momentos distintos. Esa fábrica mayoritariamente conservada pertenecería a la construcción románica, si bien combina materiales distintos, tanto en composición, color y tamaño, haciendo una especie de mosaico. Este gusto por la variedad se muestra en otros edificios propios de la transición entre la arquitectura prerrománica y la románica, como sucede en San Antolín de Toques, en algunos aspectos, y en San Martiño de Pazó en otros. También hemos visto que la sacristía actual es posterior al cuerpo de la iglesia (y no altomedieval, como se había planteado alguna vez).

Como consecuencia, y a falta de una necesaria lectura estratigráfica de todo el edificio, con los datos disponibles nos parece poco probable que se conserve en pie algo de la fábrica de la antigua iglesia prerrománica, lo cual no quiere decir que el edificio románico no reutilice una gran cantidad de piezas, posiblemente provenientes de dicha antigua iglesia (material constructivo, capiteles, fragmentos de friso...). En todo caso, de confirmarse la posibilidad de que no quede nada en pie de la iglesia prerrománica, habría que corregir la idea habitualmente sostenida de que la fábrica y la disposición de la iglesia románica estuvieron fuertemente condicionadas por una antigua iglesia altomedieval sorprendentemente ancha ${ }^{92}$.

Por su parte, el trabajo de datación ha confirmado una cronología en torno al siglo XII para la construcción de la cúpula, y nos informa además de que ésta fue realizada con ladrillos reutilizados. Se trata posiblemente de los mismos ladrillos que encontramos en otras zonas del edificio, y que podrían provenir de la primitiva edificación prerrománica que mencionan las fuentes. Como hipótesis podemos plantear que la reutilización de ladrillo para la cúpula, y las dos posibles fases detectadas en ella, podrían indicar un cambio de proyecto.

Por último, debemos insistir en la necesidad de continuar con este tipo de aproximaciones interdisciplinares, uniendo arqueología e historia del arte, a la hora de estudiar edificios de esta complejidad y densidad histórica. 
ANEXO. Tablas

\begin{tabular}{|c|c|c|c|c|}
\hline Muestra & Material & K (\%) & Th (ppm) & U (ppm) \\
\hline SMF-L1 & Ladrillo & $1,83 \pm 0,01$ & $6,16 \pm 0,47$ & $2,35 \pm 0,25$ \\
\hline SMF-L2 & Ladrillo & $1,87 \pm 0,09$ & $7,91 \pm 0,28$ & $2,82 \pm 0,15$ \\
\hline SMF-L3 & Ladrillo & $1,97 \pm 0,1$ & $6,78 \pm 0,63$ & $3,98 \pm 0,1$ \\
\hline SMF-M1 & Mortero & $0,57 \pm 0,02$ & $3,36 \pm 0,28$ & $1,69 \pm 0,06$ \\
\hline SMF-M2 & Mortero & $0,57 \pm 0,02$ & $3,36 \pm 0,28$ & $1,69 \pm 0,06$ \\
\hline SMF-P & Roca & $0,27 \pm 0,03$ & $1,57 \pm 0,06$ & $0,40 \pm 0,01$ \\
\hline
\end{tabular}

Tabla 1. Concentraciones analizadas de K, U y Th en las muestras empleadas en datación por luminiscencia.

\begin{tabular}{|c|c|c|c|c|}
\hline Muestra & $\begin{array}{c}\text { DR beta } \\
\text { (mGy/año) }\end{array}$ & $\begin{array}{c}\text { DR gamma } \\
\text { (mGy/año) }\end{array}$ & $\begin{array}{c}\text { DR cósmica } \\
\text { (mGy/año) }\end{array}$ & DR (mGy/año) \\
\hline SMF-L1 & $1,74 \pm 0,19$ & $0,40 \pm 0,02$ & $0,22 \pm 0,01$ & $2,36 \pm 0,13$ \\
\hline SMF-L2 & $1,87 \pm 0,22$ & $0,46 \pm 0,02$ & $0,22 \pm 0,01$ & $2,54 \pm 0,14$ \\
\hline SMF-L3 & $2,05 \pm 0,24$ & $0,50 \pm 0,01$ & $0,11 \pm 0,01$ & $2,66 \pm 0,16$ \\
\hline SMF-M1 & $0,69 \pm 0,07$ & $0,30 \pm 0,07$ & $0,22 \pm 0,01$ & $1,21 \pm 0,27$ \\
\hline SMF-M2 & $0,69 \pm 0,07$ & $0,39 \pm 0,02$ & $0,22 \pm 0,01$ & $1,29 \pm 0,13$ \\
\hline
\end{tabular}

Tabla 2. DRs estimadas para las muestras.

\begin{tabular}{|c|c|c|c|c|c|c|}
\hline Muestra & Material & Método & $\mathbf{N}$ & Modelo/Plateau & ED (Gy) & Sobredisp (\%) \\
\hline SMF-L1 & Ladrillo & TL & 33 & $300-390^{\circ} \mathrm{C}$ & $3,77 \pm 0,35$ & - \\
\hline & & OSL & 34 & CAM & $3,37 \pm 0,10$ & $4,6 \pm 0,7$ \\
\hline SMF-L2 & Ladrillo & TL & 31 & $300-390^{\circ} \mathrm{C}$ & $4,19 \pm 0,10$ & - \\
\hline & & OSL & 34 & CAM & $4,58 \pm 0,68$ & $9,8 \pm 1,6$ \\
\hline SMF-L3 & Ladrillo & TL & 30 & $300-390^{\circ} \mathrm{C}$ & $4,18 \pm 0,33$ & - \\
\hline SMF-M1 & Mortero & OSL & 34 & MAM & $1,02 \pm 0,29$ & $46,5 \pm 6,5$ \\
\hline SMF-M2 & Mortero & OSL & 10 & CAM & $1,56 \pm 0,08$ & $13,5 \pm 3,9$ \\
\hline
\end{tabular}

Tabla 3. EDs estimados para las muestras por medio de TL y OSL.

\begin{tabular}{|c|c|c|c|c|c|}
\hline Muestra & Material & Situación & Edad (a) & Año DC (cal) & Rango DC \\
\hline SMF-L1 & Ladrillo & Cúpula & $1429 \pm 91$ & $579 \pm 91$ & $488-671$ \\
\hline SMF-L2 & Ladrillo & Cúpula & $1653 \pm 98$ & $355 \pm 98$ & $257-453$ \\
\hline SMF-L3 & Ladrillo & Muro & $1570 \pm 153$ & $438 \pm 153$ & $284-591$ \\
\hline SMF-M1 & Mortero & Cúpula & $841 \pm 306$ & $1167 \pm 306$ & $862-1473$ \\
\hline SMF-M2 & Mortero & Cúpula & $1205 \pm 137$ & $803 \pm 137$ & $666-940$ \\
\hline SMF-M2 & Madera & Cúpula & $295 \pm 45$ & $1570 \pm 100$ & $1470-1670$ \\
\hline
\end{tabular}

Tabla 4. Edades obtenidas para los materiales datados. 


\section{NOTAS}

1 Este trabajo forma parte del proyecto "Early Medieval Churches: History, Archaeology and Heritage (EMCHAHE)", financiado por la Unión Europea a través de una ayuda Marie Curie CIG (Grant agreement: PCIG12GA-2010-334068). Los autores deseamos expresar nuestra deuda y agradecimiento con Rebeca Blanco Rotea y Luis Cordeiro Maañón, quienes generosamente han aportado interesantes informaciones y comentarios de gran valor para la realización de este trabajo. Obviamente los posibles errores y carencias de este trabajo son achacables únicamente a los autores.

2 S. Young, Britonia: Caminos nuevos, Toxosoutos, Noia, 2004. C. Baliñas Pérez, C. A. González Paz, "De Mailoc a san Rosendo: as orixes da sé mindoniense" en Rudesindus. A terra e o templo (F. Singul, Dir.), Consellería de Innovación e Industria, S.A. de Xestión do Plan Xacobeo, Santiago de Compostela, 2007, pp. 30-51. M. Carriedo Tejedo, "Locus Sancti Martini (ss. VIII-XIII)", Estudios mindonienses, 25, 2009, pp. 27-78.

3 M. Carriedo Tejedo, "Locus Sancti Martini (ss. VIII-XIII)" .., pp. 2778. M. C. Díaz y Díaz, M. A. García Piñeiro, "La Diócesis de Mondoñedo hasta 1100" en Iglesias de Lugo, Mondoñedo-Ferrol y Orense (J. García Oro, Coord.), Biblioteca de Autores Cristianos, Madrid, 2002, pp. 211-222.

4 M. Chamoso Lamas, "Las primitivas Diócesis de Britonia y de San Martín de Mondoñedo a la luz de recientes descubrimientos", Bracara Augusta, XXI, 1967, pp. 356-360. R. Yzquierdo Perrín, De arte et architectura. San Martín de Mondoñedo, Diputación Provincial de Lugo, Servicio de Publicaciones, Lugo, 1994.

5 H. Flórez, España sagrada. Teatro geográfico-histórico de la Iglesia de España. Tomo XVIII, De las Iglesias Britoniense, y Dumiense, incluidas en la actual de Mondoñedo, Antonio Marín, 1764, Madrid, p. 53

6 M. Villaamil y Castro, Iglesias gallegas de la Edad Media: Colección de artículos publicados por José Villaamil y Castro, 1904, Madrid, p. 50.
7 A. del Castillo López, Inventario de la riqueza monumental y artística de Galicia, Fundación Pedro Barrié de la Maza, 1972, A Coruña, pp. 335-336.

8 M. Chamoso Lamas, V. González, B. Regal, Galice Romane, Zodiaque, Sainte Marie de la Pierrequi-Vire, 1973.

9 M. Núñez Rodríguez, Arquitectura prerrománica, COAG, Santiago de Compostela, 1978.

10 S. Santos San Cristobal, La antigua catedral de San Martín de Mondoñedo, Talleres gráficos E. Paramé, Mondoñedo, 1980.

11 R. Yzquierdo Perrín, De arte et architectura. .

12 M. A. Castiñeiras González, "La actividad artística en la antigua provincia de Mondoñedo del Prerrománico al Románico", Estudios mindonienses: Anuario de estudios histórico-teológicos de la diócesis de Mondoñedo-Ferrol, N ${ }^{\circ} 15$, 1999, pp. 287-342. M. A. Castiñeiras González, "San Martiño de Mondoñedo (Foz) revisitado", en Rudesindus. $A$ terra e o templo, Rudesindus. A terra e o templo (F. Singul, Dir.), Consellería de Innovación e Industria, S.A. de Xestión do Plan Xacobeo, Santiago de Compostela, 2007,pp. 118-137.

13 M. A. Castiñeiras González, "Apostillas al Iter picturae sancti lacobi: las pinturas murales de San Martiño de Mondoñedo, el scriptorium compostelano y el tesorero Bernardo", Compostellanum: revista de la Archidiócesis de Santiago de Compostela, 2011, pp. 303-340. B. Besteiro, "As pinturas murais da catedral de San Martiñode Mondoñedo. Foz (Lugo)", Estudios Mindonienses, 25, 2009, pp. 79-104.

14 A. López Valcarcel, "Iglesias románicas de la Provincia de Lugo. Papeleta 166. Iglesia parroquial de San Martín de Mondoñedo", Boletín de la Comisión Provincial de Monumentos de Lugo, T. VII, 1963, pp. 151-157.

15 N. Peinado Gómez, La Antigua Catedral de San Martín de Mondoñedo (Foz). Notas arqueológicas, Caja de Ahorros de La Coruña y Lugo, 1972, Lugo.

16 N. Rielo Carballo, "Mondoñedo, Monasterio de San Martiño de", en Gran Enciclopedia Gallega (R. Otero Pedrayo, Dir.), T. XXI, Ed. Silverio Cañada, Santiago, s. a., pp. 149-152.
17 J. Yarza Luaces, "Frontal de San Martiño de Mondoñedo", en Galicia no Tempo. Catálogo (J. M. García Iglesias coord.), Arzobispado, Diócesis de Galicia, Consellería de Cultura e Xuventude, Santiago de Compostela, 1991, pp. 184-185. J. Yarza Luaces, "Artes figurativas románicas en Galicia antes de 1150", en El arte románico en Galicia y Portugal-A arte românica em Portugal e Galiza (J. C. Valle Pérez, Coord.), Madrid-Lisboa, 2001, pp. 56-87.

18 I. Bango Torviso, Galicia Románica, Biblioteca da Cultura Galega, Galaxia, Vigo, 1987. I. Bango Torviso, "Arquitectura románica en Galicia. Desde los orígenes hasta 1168" El arte románico en Galicia y Portugal-A arte românica em Portugal e Galiza (J. C. Valle Pérez, Coord.), Fundación Pedro Barrié de La Maza-Fundaçao Calouste Gulbenkian, Madrid-Lisboa, 2001, pp. 12-30.

19 M. Núñez Rodríguez, Arquitectura..., p. 243.

${ }^{20}$ Ibídem, p. 245.

${ }^{21}$ R. Yzquierdo Perrín, Arte Medieval (I), Hércules de Ediciones, A Coruña, 1993, p. 137.

22 Ibidem, p. 134-137.

23 R. Yzquierdo Perrín, "Arte prerrománica na diocese de Mondoñedo", en Rudesindus. A terra e o templo, Rudesindus. A terra e o templo (F. Singul, Dir.), Consellería de Innovación e Industria, S.A. de Xestión do Plan Xacobeo, Santiago de Compostela, 2007, pp. 100-117.

24 M. A. Castiñeiras González, "San Martiño de Mondoñedo...", p. 120.

25 Ibídem, p. 125.

${ }^{26}$ R. Yzquierdo Perrín, "Diego Gelmírez y los inicios del Románico en Galicia", en O século de Xelmírez (F. López Alsina, H. Monteagudo, R. Villares, R. Yzquierdo Perrín, Coords.), Consello da Cultura Galega, Santiago de Compostela, 2013, p. 215.

27 M. A. Castiñeiras González, "La actividad artística...", p. 305.

${ }^{28}$ A. del Castillo López, Inventario de la riqueza monumental y artística de Galicia..., p. 336

29 J. Yarza Luaces, "Frontal de San Martiño..., pp. 184-185. 
30 Para algunas reflexiones a este respecto Vid. J. Castiñeiras López, "Imágenes de conflicto: la influencia de los Beatos en San Martiño de Mondoñedo" en El legado hispánico: manifestaciones culturales y sus protagonistas (A. Lobato Fernández, E. de los Reyes Aguilar, I. Pereira García, C. García González, Eds.), Universidad de León. Área de Publicaciones, León, 2016, pp. 251-272.

31 I. Bango Torviso, Galicia..., p. 26. R. Yzquierdo Perrín, De arte et architectura..., p. 55.

32 R. Yzquierdo Perrín, De arte et architectura..., p. 51.

33 Ibidem, p. 46.

${ }^{34} \mathrm{M}$. Villaamil y Castro, Iglesias gallegas de la Edad Media..., p. 39.

35 M. A. Castiñeiras González, "San Martiño de Mondoñedo...", p. 123.

${ }^{36}$ R. Yzquierdo Perrín, "Diego Gelmírez y los inicios del Románico...", p. 225.

37 R. Yzquierdo Perrín, De arte et architectura..., pp. 54-55.

${ }^{38}$ M. A. Castiñeiras González, "La actividad artística...", p. 306.

39 M. A. Castiñeiras González, "San Martiño de Mondoñedo...", p. 127.

${ }^{40}$ M. Chamoso Lamas, M. Chamoso Lamas, "Las primitivas Diócesis de Britonia...", pp. 356-360.

41 Ibídem, p. 357 para la nota.

42 Ibídem.

43 Ibidem.

${ }^{44}$ M. Núñez Rodríguez, Arquitectura..., p. 242. M. Núñez Rodríguez, "Inscripciones de la Galicia Altomedieval", Revista de Guimaraes, LXXXIX, 1979, pp. 309-310.

45 L. Cordeiro Maañón, C. Rodríguez Cao, "As sondaxes en San Martiño de Mondoñedo", Bolanda. Cadernos de historia fozega, 2, 2010, p. 70.

46 C. Rodríguez Cao, L. Cordeiro Maañón, "Sondaxes arqueolóxicos na horta da casa reitoral de San Martiño de Mondoñedo, Foz (Lugo)", Actuacións arqueolóxicas. Ano 2007, Santiago de Compostela, 2009, pp. 104-105. L. Cordeiro Maañón, C. Rodríguez Cao, "As sondaxes en San Martiño de Mondoñedo...", p. 70. L. Cordeiro Maañón,
C. Rodríguez Cao "Nuevas aportaciones para el estudio de la necrópolis medieval de la basílica de San Martiño de Mondoñedo (Foz, Lugo)", Jornadas territorio y urbanismo, Braga, Braga, en prensa.

47 L. Cordeiro Maañón, C. Rodríguez Cao "Nuevas aportaciones para el estudio...".

48 Ibídem.

50 L. Cordeiro Maañón, C. Rodríguez Cao "Nuevas aportaciones para el estudio...".

51 F. Arias Vilas, "Chamoso Lamas e a arqueoloxía lucense: unha revisión", en Lugo no obxectivo de Manuel Chamoso Lamas, Real Academia Gallega de Bellas Artes de Nuestra Señora del Rosario, Lugo, 1995, pp. 39-59, p. 46 para la nota.

52 J. Suárez Otero, "Sobre las laudas de "doble estola" en Santiago de Compostela e Iria Flavia", Abrente, N. 29, A Coruña, 1997, pp. 41-47.

${ }^{53}$ M. Núñez Rodríguez, Arquitectura..., p. 244.

54 R. Yzquierdo Perrín, Arte..., p. 137.

55 R. Yzquierdo Perrín, "Arte prerrománica..."", p. 104.

56 M. Núñez Rodríguez, Arquitectura..., p. 243.

57 M. A. Castiñeiras González, "San Martiño de Mondoñedo (Foz) revisitado", p. 120.

58 M. Núñez Rodríguez, Arquitectura..., p. 239.

59 R. Yzquierdo Perrín, Arte..., p. 135. R. Yzquierdo Perrín, "Arte prerrománica...", p. 110.

60 M. Núñez Rodríguez, Arquitectura..., p. 244

61 M. A. Castiñeiras González, "San Martiño de Mondoñedo...", p. 120.

62 R. Yzquierdo Perrín, "Arte prerrománica...", p. 113.

63 R. Yzquierdo Perrín, De arte et architectura...

64 M. Núñez Rodríguez, Arquitectura..., p. 244. M. A. Castiñeiras González, "San Martiño de Mondoñedo...", p. 121.
65 R. Yzquierdo Perrín, Arte..., p. 136. Idem, "Arte prerrománica ...", p. 110.

66 M. Núñez Rodríguez, Arquitectura..., p. 244. M. A. Castiñeiras González, "San Martiño de Mondoñedo...", p. 121.

${ }_{67}$ M. Chamoso Lamas, "Las primitivas Diócesis de Britonia...", p. 356.

68 R. Yzquierdo Perrín, Arte..., p. 135.

${ }^{69}$ M. Núñez Rodríguez, Arquitectura..., p. 245.

70 R. Yzquierdo Perrín, Arte..., p. 135. Idem, "Arte prerrománica...", p. 104.

71 M. A. Castiñeiras González, "San Martiño de Mondoñedo...", p. 121.

72 M. A. Utrero Agudo, I. Sastre de Diego (2012), "Reutilizando materiales en las construcciones de los siglos VIIX. ¿Una posibilidad o una necesidad?" Anales de Historia del Arte Vol. 22, Num. Especial (II), Madrid, pp. 309-323.

73 R. Yzquierdo Perrín, "Arte prerrománica...", p. 112.

${ }^{74}$ M. Chamoso Lamas, M. Chamoso Lamas, "Las primitivas Diócesis de Britonia...", pp. 356-360.

75 R. Yzquierdo Perrín, Arte..., p. 135. Yzquierdo en este trabajo de 1993 cree que Chamoso se debió guiar falsamente por el aparejo del exterior del muro oriental (de sillarejo alternado con una hilada de pizarra dispuesta en diagonal), sin darse cuenta que este muro debió adosarse al cierre sur del crucero posteriormente a su construcción ya que reutiliza, entre otras piezas, tres canecillos románicos.

76 R. Yzquierdo Perrín, "Arte prerrománica...", p. 110.

77 Ibídem.

78 L. Cordeiro Maañón, C. Rodríguez Cao "Nuevas aportaciones para el estudio..."

79 Ibídem.

80 J. Sanjurjo-Sánchez, "Dating historical buildings: an update on the possibilities of absolute dating methods", International Journal of Architectural Heritage, 10, 2016, 620-635.

81 J. Sanjurjo-Sánchez, "Dating historical buildings...". 
${ }^{2} \quad$ M. J. Aitken, Thermolumines-

을 cence dating, Academic Press, London, 1985.

83 J. Sanjurjo-Sánchez, "Dating historical buildings...".

${ }^{84}$ G. Guerin, N. Mercier, G. Adamiec, "Dose-rate conversion factors: update", Ancient TL, 29, 2011, pp. 5-8. J. R. Prescott, J. T. Hutton, "Cosmic ray contributions to dose rates for luminescence and ESR dating: large depths and long term variations", Radiation Measurements, 23, 1994, 497-500.

85 M. J. Aitken, Thermoluminescence dating, Academic Press, London, 1985.
${ }^{86}$ A. S. Murray, A. G. Wintle, "The single aliquot regenerative dose protocol: Potential for improvements in reliability", Radiation Measurements, 37 (4-5), 2003, 377-381. Idem, "Luminescence dating of quartz using an improved single-aliquot regenerative-dose protocol", Radiation Measurements, 32, 2000, 57-73.

87 M. J. Aitken, Thermoluminescence dating

88 R. F. Galbraith, R. F., R. G. Roberts, G. M. Laslett, H. Yoshida, H. Olley, "Optical dating of single and multiple grains of quartz from Jinmium Rock Sherlter, Northern Australia: Part
1, Experimental design and statistical models", Archaeometry, 41, 1999, 339-364.

89 Ibidem.

90 S. Blain, "An application of luminiscence dating to building archaeology: The study of ceramic building materials in early medieval churches in north-western France and southeastern England", Arqueología de la Arquitectura, 7, 2010, pp. 43-66.

91 J. Sanjurjo-Sánchez, "Dating historical buildings...".

92 M. Núñez Rodríguez, Arquitectura..., p. 135. 


\section{REFERENCIAS}

Aitken, Martin Jim. 1985. Thermoluminescence dating. London: Academic Press.

Arias Vilas, Felipe. 1995. "Chamoso Lamas e a arqueoloxía lucense: unha revisión." In Lugo no obxectivo de Manuel Chamoso Lamas, 39-59. A Coruña: Real Academia Gallega de Bellas Artes de Nuestra Señora del Rosario.

Baliñas Pérez, Carlos, and Carlos Andrés González Paz. 2007. "De Mailoc a san Rosendo: as orixes da sé mindoniense." In Rudesindus. A terra e o templo, edited by Francisco Singul, 30-51. Santiago de Compostela: Consellería de Innovación e Industria, S.A. de Xestión do Plan Xacobeo.

Bango Torviso, Isidro. 1987. Galicia Románica. Biblioteca da Cultura Galega. Vigo: Galaxia.

Bango Torviso, Isidro. 2001. "Arquitectura románica en Galicia. Desde los orígenes hasta 1168." In El arte románico en Galicia y Portugal-A arte românica em Portugal e Galiza, edited by José Carlos Valle Pérez, 12-30. Madrid-Lisboa: Fundación Pedro Barrié de La Maza-Fundaçao Calouste Gulbenkian.

Besteiro, Blanca. 2009. "As pinturas murais da catedral de San Martiño de Mondoñedo. Foz (Lugo)." Estudios Mindonienses 25: 79-104.

Blain, Sophie. 2010. "An application of luminiscence dating to building archaeology: The study of ceramic building materials in early medieval churches in north-western France and south-eastern England." Arqueología de la Arquitectura 7: 43-66. https://doi.org/10.3989/ arqarqt.2010.10004

Carriedo Tejedo, Manuel. 2009. "Locus Sancti Martini (ss. VIII-XIII)." Estudios mindonienses 25: 27-78.

Castillo López, Ángel del. 1972. Inventario de la riqueza monumental y artística de Galicia. A Coruña: Fundación Pedro Barrié de la Maza.

Castiñeiras González, Manuel Antonio. 1999. “La actividad artística en la antigua provincia de Mondoñedo del Prerrománico al Románico." Estudios mindonienses: Anuario de estudios histórico-teológicos de la diócesis de Mondoñedo-Ferrol 15: 287-342.
Castiñeiras González, Manuel Antonio. 2007. "San Martiño de Mondoñedo (Foz) revisitado." In Rudesindus. A terra e o templo, Rudesindus. A terra e o templo, edited by Francisco Singul, 118-137. Santiago de Compostela: Consellería de Innovación e Industria, S.A. de Xestión do Plan Xacobeo.

Castiñeiras González, Manuel Antonio. 2011. "Apostillas al Iter picturae sancti lacobi: las pinturas murales de San Martiño de Mondoñedo, el scriptorium compostelano y el tesorero Bernardo." Compostellanum: revista de la Archidiócesis de Santiago de Compostela: 303-340.

Castiñeiras López, Javier. 2016. “Imágenes de conflicto: la influencia de los Beatos en San Martiño de Mondoñedo." In El legado hispánico: manifestaciones culturales y sus protagonistas, 251-272. León: Universidad de León.

Chamoso Lamas, Manuel. 1967. "Las primitivas Diócesis de Britonia y de San Martín de Mondoñedo a la luz de recientes descubrimientos." Bracara Augusta XXI: 356-360.

Chamoso Lamas, Manuel, Victoriano González, and Bernardo Regal. 1973. Galice Romane. Sainte Marie de la Pierrequi-Vire: Zodiaque.

Cordeiro Maañón, Luís and Rodríguez Cao, Celso. 2010. "As sondaxes en San Martiño de Mondoñedo." Bolanda. Cadernos de historia fozega 2: 70.

Cordeiro Maañón, Luís, and Celso Rodríguez Cao. En prensa. "Nuevas aportaciones para el estudio de la necrópolis medieval de la basílica de San Martiño de Mondoñedo (Foz, Lugo)." Jornadas territorio y urbanismo, Braga, Braga.

Díaz y Díaz, Manuel Cecilio and María Araceli García Piñeiro. 2002. "La Diócesis de Mondoñedo hasta 1100." In Iglesias de Lugo, Mondoñedo-Ferrol y Orense, edited by José García Oro, 211-222. Madrid: Biblioteca de Autores Cristianos.

Flórez, Henrique. 1764. España sagrada. Teatro geográfico-histórico de la Iglesia de España. Tomo XVIII, De las Iglesias Britoniense, y Dumiense, incluídas en la actual de Mondoñedo. Madrid: Antonio Marín. 
Galbraith, Rex, Roberts, Richard Laslett, Yoshida Geoff, and Olley Jon Hiroshi. 1999. "Optical dating of single and multiple grains of quartz from Jinmium Rock Sherlter, Northern Australia: Part 1, Experimental design and statistical models." Archaeometry 41: 339-364. https://doi.org/10.1111/j.1475-4754.1999. tb00987.x

Guerin, Guillaume, Norbert Mercier, and Grzegorz Adamiec. 2011. "Dose-rate conversion factors: update." Ancient TL 29: 5-8.

López Valcarcel, Amador. 1963. "Iglesias románicas de la Provincia de Lugo. Papeleta 166. Iglesia parroquial de San Martín de Mondoñedo." Boletín de la Comisión Provincial de Monumentos de Lugo VII: 151-157.

Murray, Andrew Sean, and Ann Wintle. 2000. "Luminescence dating of quartz using an improved single-aliquot regenerative-dose protocol." Radiation Measurements 32: 57-73. https:// doi.org/10.1016/S1350-4487(00)00089-5 https://doi.org/10.1016/S13504487(99)00253-X

Murray, Andrew Sean, and Ann Wintle. 2003. "The single aliquot regenerative dose protocol: Potential for improvements in reliability." Radiation Measurements 37 (4-5): 377-381. https://doi.org/10.1016/ S1350-4487(03)00053-2

Núñez Rodríguez, Manuel. 1979. "Inscripciones de la Galicia Altomedieval." Revista de Guimaraes LXXXIX: 309-310.

Núñez Rodríguez, Manuel. 1978. Arquitectura prerrománica. Santiago de Compostela: COAG.

Peinado Gómez, Narciso. 1972. La Antigua Catedral de San Martín de Mondoñedo (Foz). Notas arqueológicas. Lugo: Caja de Ahorros de La Coruña y Lugo.

Prescott, John. R, and John T. Hutton. 1994. "Cosmic ray contributions to dose rates for luminescence and ESR dating: large depths and long term variations." Radiation Measurements 23: 497-500. https://doi. org/10.1016/1350-4487(94)90086-8

Rielo Carballo, Nicanor. 1974. "Mondoñedo, Monasterio de San Martiño de." In Gran En- ciclopedia Gallega, T. XXI, 149-152. Santiago: Ed. Silverio Cañada.

Rodríguez Cao, Celso, and Luis Cordeiro Maañón. 2009. "Sondaxes arqueolóxicos na horta da casa reitoral de San Martiño de Mondoñedo, Foz (Lugo)." In Actuacións arqueolóxicas. Ano 2007, 104-105. Santiago de Compostela: Xunta de Galicia.

Sanjurjo-Sánchez, Jorge. 2016. "Dating historical buildings: an update on the possibilities of absolute dating methods." International Journal of Architectural Heritage 10: 620-635. https:// doi.org/10.1080/15583058.2015.1055384

Santos San Cristobal, Sebastián. 1980. La antigua catedral de San Martín de Mondoñedo. Mondoñedo: Talleres gráficos E. Paramé.

Suárez Otero, José. 1997. "Sobre las laudas de "doble estola" en Santiago de Compostela e Iria Flavia." Abrente 29: 41-47.

Utrero Agudo, María de los Ángeles, and Isaac Sastre de Diego. 2012, "Reutilizando materiales en las construcciones de los siglos VII-X. ¿Una posibilidad o una necesidad?" Anales de Historia del Arte 22, II: 309-323.

Villaamil y Castro, José. 1904. Iglesias gallegas de la Edad Media: Colección de artículos publicados por José Villaamil y Castro. Madrid.

Yarza Luaces, Joaquín. 1991. "Frontal de San Martiño de Mondoñedo." In Galicia no Tempo. Catálogo, edited by José María García Iglesias, 184-185. Santiago de Compostela: Consellería de Cultura e Xuventude.

Yarza Luaces, Joaquín. 2001. "Artes figurativas románicas en Galicia antes de 1150." In El arte románico en Galicia y Portugal-A arte românica em Portugal e Galiza, edited by José Carlos Valle Pérez, 56-87. Madrid-Lisboa: Fundación Pedro Barrié de la Maza.

Young, Simon. 2004. Britonia: Caminos nuevos. Noia: Toxosoutos.

Yzquierdo Perrín, Ramón. 1993. Arte Medieval (I). A Coruña: Hércules de Ediciones.

Yzquierdo Perrín, Ramón. 1994. De arte et architectura. San Martín de Mondoñedo. Lugo: Diputación Provincial de Lugo. 
Yzquierdo Perrín, Ramón. 2007. "Arte prerrománica na diocese de Mondoñedo." In Rudesindus. A terra e o templo, Rudesindus. A terra e o templo, edited by Francisco Singul, 100-117. Santiago de Compostela: Consellería de Innovación e Industria, S.A. de Xestión do Plan Xacobeo.
Yzquierdo Perrín, Ramón. 2013. “Diego Gelmírez y los inicios del Románico en Galicia." In $O$ século de Xelmírez, edited by Fernando López Alsina, Henrique Monteagudo, Ramón Villares, Ramón Yzquierdo Perrín, 207-243. Santiago de Compostela: Consello da Cultura Galega. 
